\title{
Are common fragile sites merely structural domains or highly organized "functional" units susceptible to oncogenic stress?
}

\author{
Alexandros G. Georgakilas • Petros Tsantoulis • \\ Athanassios Kotsinas • Ioannis Michalopoulos • \\ Paul Townsend • Vassilis G. Gorgoulis
}

Received: 28 August 2014/ Accepted: 28 August 2014/Published online: 20 September 2014

(C) The Author(s) 2014. This article is published with open access at Springerlink.com

\begin{abstract}
Common fragile sites (CFSs) are regions of the genome with a predisposition to DNA double-strand breaks in response to intrinsic (oncogenic) or extrinsic replication stress. CFS breakage is a common feature in carcinogenesis from its earliest stages. Given that a number of oncogenes and tumor suppressors are located within CFSs, a question that emerges is whether fragility in these regions is only a structural "passive" incident or an event with a profound biological effect. Furthermore, there is sparse evidence that other elements, like noncoding RNAs, are positioned with them. By analyzing data from various libraries, like miRbase and ENCODE, we show a prevalence of various cancer-related genes, miRNAs, and regulatory binding sites, such as CTCF
\end{abstract}

A. G. Georgakilas, P. Tsantoulis, and A. Kotsinas contributed equally to this manuscript.

\section{A. G. Georgakilas}

Physics Department, School of Applied Mathematical and

Physical Sciences, National Technical University of Athens

(NTUA), Zografou, 15780 Athens, Greece

P. Tsantoulis

Division of Oncology, Geneva University Hospitals,

1211 Geneva, Switzerland

A. Kotsinas · V. G. Gorgoulis

Molecular Carcinogenesis Group,

Department of Histology and Embryology,

School of Medicine, University of Athens,

11527 Athens, Greece

\section{Michalopoulos}

Computational Biology and Medicine,

Center of Systems Biology, Biomedical Research

Foundation of the Academy of Athens,

4 Soranou Efessiou, 11527 Athens, Greece within CFSs. We propose that CFSs are not only susceptible structural domains, but highly organized "functional" entities that when targeted, severe repercussion for cell homeostasis occurs.

Keywords Fragile sites $\cdot$ miRNAs $\cdot$ Genomic instability · DNA elements · DNA repair · Carcinogenesis

\section{Introduction}

Activated oncogenes are a key feature of cancer development from its earliest stages [1]. One of their major effects is the induction of DNA damage via replication stress (RS) [2]. Specifically, oncogene-induced DNA replication stress (OIRS) leads to the formation of DNA double-strand breaks (DSBs), due to replication forks

\section{P. Townsend · V. G. Gorgoulis}

Faculty Institute for Cancer Sciences, University of Manchester, Manchester Academic Health Science Centre, Manchester M13 9WL, UK

e-mail: p.a.townsend@manchester.ac.uk

P. Townsend · V. G. Gorgoulis

Manchester Centre for Cellular Metabolism, University of Manchester, Manchester Academic Health Science Centre,

Manchester M13 9WL, UK

V. G. Gorgoulis

Biomedical Research Foundation of the Academy of Athens, 4 Soranou Efessiou, 11527 Athens, Greece

V. G. Gorgoulis ( $\square)$

Department of Histology-Embryology, Medical School, National Kapodistrian University of Athens, 75 Mikras Asias Str., Goudi, 11527 Athens, Greece

e-mail: vgorg@med.uoa.gr 
(RFs) collapse, fueling genomic instability (GI) [2, 3]. In early precancerous lesions, the collapse of DNA RFs occurs preferentially at specific loci termed fragile sites (FSs) [4]. As a result, FSs exhibit breaks, gaps, and rearrangements, collectively termed FSs expression. This is due to the activation of pathways responsible for fork collapse resolution and completion of DNA replication, which involve recombinogenic processes and DNA DSBs production [2].

An important issue is whether the instability manifested at these sites has any wider biological impact on cancer development. As further discussed in the manuscript, although FSs are heterogeneous in their expression patterns, they possess unique features that make them vulnerable to structural destabilization under RS conditions. Are these regions simply prone to DNA damage due to their intrinsic characteristics, conferring only to GI? Sparse evidence indicates that FSs enclose genes and non-coding RNAs, like microRNAs (miRs), while their expression could be epigenetically modulated by histones, implying that they are regions of the genome of a higher organization level (Fig. 1) [5-9]. Important bioinformatic resources are currently available and can be exploited to define potential topological associations between CFSs and these elements. Notably, the miRbase is constantly expanding while the ENCODE project [10] has deposited information on a vast range of binding elements and genomic modifications, including histone marks (like H3K79me2, H3K9ac, H3K4me3, and $\mathrm{H} 3 \mathrm{~K} 27 \mathrm{ac}$ ) that have a prominent influence on the expression process of the genome. As the pattern of instability at FSs in human tumors is variable, suggesting that it also depends on the cell type, this further complicates the role of FSs in malignancy. Last but not least, if such sites contribute to cancer development, why have they not been evolutionary selected for elimination? Could there be a higher reason that makes them at the same time vulnerable "units" of the genome with potentially meaningful function? Attempting to address these questions, in the current work we conducted an extensive review on the nature of their heterogeneity that accounts for their preferential instability. Next, by applying bioinformatic tools on data from the latest miRbase and the ENCODE project, we reveal that these sites are enriched in various (coding and non-coding) elements, such as cancer-related genes, miRs, and binding elements, as well as specific variations in histone modifications (Fig. 1). Based on these findings, we propose that these sites may represent unique "functional" units of the genome that may have a complex role upon OIRS with implications both in normal cell survival and cancer progression.

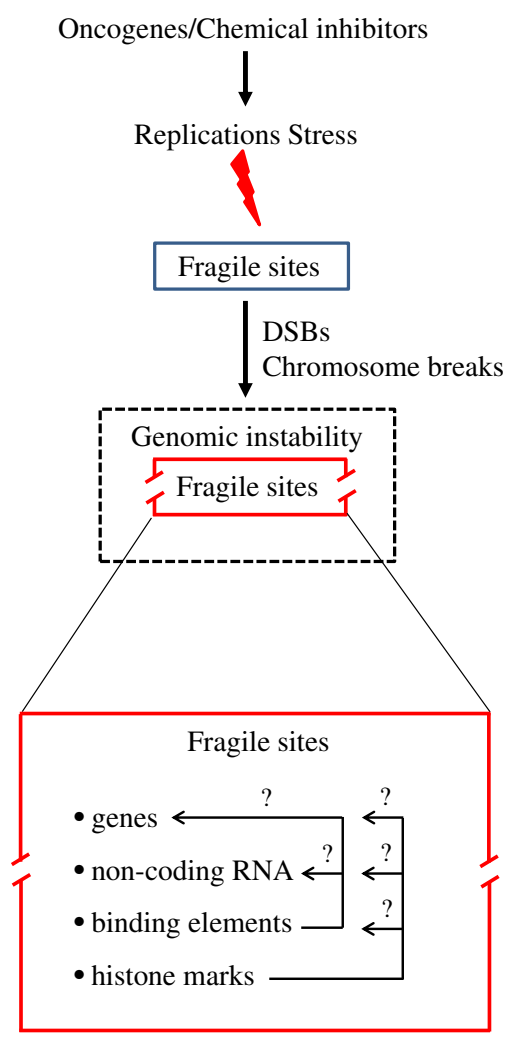

Fig. 1 CFSs are not only vulnerable structural domains but may also be functional units of the genome that are sensitive to replication stress. CFS's stability is affected by replications stress (RS). During cancer development, they are affected from the earliest precancerous lesions due to oncogene-induced replication stress (OIRS). Breakage at CFSs (broken red rectangle) may not only confer to genomic instability (GI) (dashed black rectangle), but could also have wider biological implications by affecting elements located within them (question mark). DSBs DNA double-strand breaks

\section{Heterogeneity of fragile sites}

FSs have been assigned in two classes, defined as rare fragile sites (RFSs) and common fragile sites (CFSs). Rare FSs are mainly induced by folate deficiency, correspond to dinucleotide or trinucleotide repeats, usually $\mathrm{CGG}_{\mathrm{n}}$, and are found in less than $5 \%$ of the human population and in specific families [11]. Their fragility is due to expansions of the micro- or mini-satellites sequences that they contain and in some cases are responsible for inherited diseases [11]. Therefore, RFSs will not be further discussed in this work.

Historically, CFSs were recognized as recurrent hotspots of double-stranded DNA breaks in cultured lymphocytes from healthy individuals [12]. They are present in all individuals, are part of the normal chromosomes, but exhibit different frequencies of expression in a population (reviewed in [13, 14]). CFSs are typically vulnerable to extrinsic replication stress, most notably to aphidicolin (APH), an inhibitor of DNA polymerase $\alpha, \delta$ and $\varepsilon$, but are 
otherwise quiescent under normal conditions. This observation has been gradually broadened to include breakage patterns resulting from various replication inhibitors, such as nucleotide analogs (5-azacytidine, bromodeoxyuridine) or antitumor antibiotics (distamycin) and RS resulting from folate deficiency. Dietary and environmental factors like caffeine, cigarette smoke, and hypoxia may also enhance FS expression [15]. Recently, the induction of stress during the early $\mathrm{S}$ phase in B lymphocytes by hydroxyurea has been found to provoke DNA damage in a distinct pattern, corresponding to a new class of "early replicating fragile sites" (ERFSs) [16]. They occur primarily in early replicating DNA, close to replication origins, and are mainly situated in actively transcribed gene clusters (coding regions) [17]. This contrasts with CFSs, like FRA3B, which are most sensitive during their replication in late $S$ phase [18]. Nevertheless, ERFSs seem also to arise from RF collapse and are similarly sensitive to ATR inhibition and oncogene-induced stress (see A. Nussenzweig chapter in this issue). OIRS is expected to induce instability at both ERFS and CFS, as suggested in two independent studies $[16,19]$. Recent reports using the phosphorylated form of histone $\mathrm{H} 2 \mathrm{AX}$, the $\gamma-\mathrm{H} 2 \mathrm{AX}$, as a marker of DSB induction showed that ERFS were enriched for H2AX and $\gamma-\mathrm{H} 2 \mathrm{AX}$, while CFSs and heterochromatin lacked both, also suggesting differential DNA damage response at these sites [20]. Notably, both ERFSs and CFSs are rich in CpG-rich regions [17, 19], implying that these classes of FSs may either share structural similarities or the exact classification of their members as early and late replicating ones may need further re-assessment. Surprisingly, telomeric regions also appear to exhibit fragility in a similar manner as CFSs upon replication stress, including APH treatment [21].

It has been shown that CFS expression patterns depend not only on culture conditions but also on cell type [22]. Although traditionally studied almost exclusively in lymphocytes, different CFSs have been observed in fibroblasts $[22,23]$, breast, and colon epithelial cell lines [24, 25] and erythroid cell lines [25]. Considerable overlap exists between experiments, but the relative frequency of CFS breaks varies significantly. For example, FRA3B is the most frequent fragile locus in lymphocytes, but does not seem to be fragile in epithelial cell lines [24, 26], possibly due to the plasticity of replication programs in different cell lineages or because of a putative "housekeeping" role of FHIT. The second most fragile site, FRA16D, is very frequently affected in epithelial breast cancer cell lines (20-25\%), but only occasionally in colon epithelial cells $(\sim 5 \%)$. Clearly, a complete characterization of CFS breakage probabilities will require a panel of different cell types.

CFSs are found in different individuals and are conserved across different species, including the mouse, the rat, and many mammals [27, 28], and across kingdoms, such as in the yeast $S$. cerevisiae [29]. Evolutionary conservation could argue in favor of a meaningful function if CFSs are considered outliers compared with the overall fragility of the genome in general. Nevertheless, variation between individuals can be significant. In a study of 20 normal adults [30], only FRA3B and FRA16D were found to be fragile in all individuals, and only $42 \%$ of CFSs (19 of 45 identified) were present in the majority of individuals. In the earliest studies, less than 20 CFSs would explain more than $80 \%$ of gaps and breaks [12]. A similar distribution was found in a population study of Deer mice, where high-frequency CFSs constituted approximately $26 \%$ of the population total breaks and $38 \%$ of CFSs were only found in single individuals.

\section{Fragility of CFS}

The issue of fragility at CFSs is a matter of intensive investigation. CFSs replicate either late in S-phase or initiate replication in mid-S phase, but exhibit a significant delay in completing it. Under conditions of RS, they may remain unreplicated even during G2-phase and up to mitosis leading eventually to their instability (as discussed in next section and reviewed in [13, 14]). Several features responsible for their replication sensitivity have not been revealed until now. These include intrinsic structural characteristics, the presence and overlap with large genes, differences in replication features, and epigenetic modulation [13, 14].

At the structural level, CFSs have the propensity to form secondary non-B structures that interfere with the movement of the replication fork thus leading to its collapse and associated DNA breaks [31]. Specifically, at sequence level, CFS are enriched in long stretches of AT dinucleotide-rich repeats that may form stable secondary cruciform DNA structures inducing fork stalling during DNA replication and in general incomplete or delayed DNA replication [31, 32]. In an earlier study, we performed a whole-genome analysis of CFS sequences and observed that they are on average rich in GC and Alu sequences [19]. The Alu family is a family of short interspersed repetitive elements (SINE) of about $300 \mathrm{bp}$ containing mid and terminal poly A-stretches [33]. Interestingly, these elements are the most abundant mobile elements, and thus potentially recombinogenic in the human genome, and are implicated in various inherited human diseases and in cancer [34].

CFSs have been associated with genes extending over long genomic regions ("large genes") [5]. The FHIT gene in FRA3B and WWOX in FRA16D are striking examples, measuring approximately 1.5 and $1.1 \mathrm{Mb}$ respectively, compared with a mean of $10-15 \mathrm{~kb}$ for protein coding 
genes. The PARK2 gene, at approximately $1.4 \mathrm{Mb}$ is also associated with FRA6E and may be down-regulated in ovarian tumors [30]. Intriguingly, genes over $800 \mathrm{~kb}$ may be prone to form RNA:DNA hybrid loops (termed R-loops) at sites of replication-transcription collision [35]. R-loops are structures formed by the association of the nascent transcript with the DNA template strand leaving unpaired the complementary non-coding DNA strand. Replication of large genes is time consuming and exposes the replication machinery to a risk of collision with the transcriptional machinery. In such an occurrence, the elongating RNA polymerase is blocked, leading to increased R-loop formation at Pol II pause sites. As a result, collision events may induce CFS breakage and a consequent enhancement of genomic instability [35].

Recent data have shed new light on the dynamics of the replication process at CFSs, providing several new mechanistic aspects explaining their instability (reviewed in [13, 14]). In the first one, it was shown that stability of FRA16C is perturbed under RS, as RFs progress more slowly and stall upon accounting AT-rich regions within this site. While in the bulk genome dormant origins are activated to complete replication, these are not available within FRA16C leading to delayed replication and instability [14] (also see B. Kerem chapter in this issue). A second report studying the mechanistic fragility of FRA3B, showed that fork speed slowing and stalling is similar with respect to the bulk genome, even under RS [26] (also see M. Debatisse chapter in this issue). In this case, the inability to complete replication was attributed to a large $700-\mathrm{kb}$ core within this site that was found to be poor in origins. To accomplish replication of this site, origins from a long distance, located in the flanking regions, are required to come in and cover its length. The density and timing of origin firing events in the flanking regions seem to dictate the timing of FRA3B replication completion, thus influencing its stability. In a third mechanistic model regarding the FRA6E site, both replication arrest and paucity of origin activation lead to RS sensitivity, providing a functional combination of the two previous models [36]. Interestingly, some CFSs like the FRA3B do not exhibit stably these replication features in each cell type, suggesting that CFSs may demonstrate different patterns of instability, which are tissue specific. This may also explain why in various malignancies distinct profiles of GI are observed at CFSs that characterize each type of cancer. It would be interesting in the future to define the replication behavior of each CFS according to the specific cell type. That would be helpful in defining and possibly predicting the precise patterns of GI that take place during cancer development.

The replication density and timing of the genome has been proposed to be highly flexible and epigenetically controlled rather than directed by specific sequence motifs
[13]. Therefore, an epigenetic control of CFSs replication stability may also apply. In support of this is the observed H3K9/14 hypoacetylation pattern displayed by the six most expressed CFSs in lymphoblastoid cells [9]. This histone modification has been reported to be associated with chromatin compactness and increased breakage. Also, regions with evenly spaced nucleosomes, an unusual chromatin structure preferentially formed at promoters and regulatory binding sites, have also been observed in FRA3B [37].

Overall, it seems that there is no single mechanism that can explain the fragility of CFSs but rather a multitude. They depend on several characteristics, including structural properties of the FSs as well as dynamic features governing their replication that apply in a given cell type. Interestingly, they are not necessarily mutually exclusive and often can function in complementary ways [13, 14]. The only common shared aspect by all these mechanisms is that they can eventually lead to a mechanical breakage of CFSs.

\section{Maintenance of fragile site integrity}

Instability at FSs is a recognized signature of DNA damage induced by replication stress [2] and it is detected from the earliest premalignant stages $[3,4,19]$. Replication checkpoints are activated in response to the stress induced at CFSs [38]. Central to these checkpoints are the DNA damage response kinases, ATM and ATR, which respectively sense DNA double-strand breaks and RF integrity [38]. Specific targeting of these kinases in cellular models revealed that ATR disruption or hypomorphic mutations lead to chromosomal instability within CFS even under normal replication, a phenomenon that is aggravated after low doses of APH [39]. In addition, dual inhibition of ATM and ATR using caffeine has been found to significantly increase CFS breakage compared with ATR deficiency alone, denoting also a role for ATM and a possible interplay with ATR in CFS protection [40, 41]. Inactivation of several down-stream components of the ATR network like Chk1, HUS1, Claspin, and SMC1 revealed similar effects, although not as efficient as ATR loss (Table 1) [31, 42-44].

These checkpoints are vital as they ensure that DNA is replicated and chromosomes are prepared for mitosis [38]. Nevertheless, CFSs exhibit an increased vulnerability to RS leading to the activation of repair mechanisms [31]. The frequently observed presence of sister chromatid exchanges (SCEs) at the majority of CFSs breaks after APH treatment suggests that homologous recombination (HR) plays a major role in response to DSBs induced under conditions of RS [45]. The FANCD2 component of the Fanconi anemia (FA) pathway has been shown to play a role not only in HR-dependent replication recovery, but 
Table 1 Factors involved in control of CFSs stability and genome integrity

\begin{tabular}{|c|c|c|}
\hline Factor & Function & Reference \\
\hline ATR & Main kinase-activating replication checkpoint & {$[39,75]$} \\
\hline ATM & Complementary acting kinase & [76] \\
\hline Chk1 & Main ATR-downstream kinase involved in activation of the replication checkpoint & {$[31]$} \\
\hline Chk2 & ATM-downstream kinase & [76] \\
\hline HUS1 & $\begin{array}{l}\text { Participates in the Rad9-Rad1-Hus1 (9-1-1) complex and is homologous to the PCNA clamp. The complex } \\
\text { phosphorylates ATR substrates upon loading to sites of DNA damage }\end{array}$ & [42] \\
\hline Claspin & $\begin{array}{l}\text { Encodes for an adaptor protein which binds to BRCA1 and Chk1 and facilitates the ATR-dependent } \\
\text { phosphorylation of both proteins during DNA replication stress in human cells }\end{array}$ & [43] \\
\hline SMC1 & $\begin{array}{l}\text { Member of the family of "structural maintenance of chromosomes" proteins participating in chromosome } \\
\text { condensation, sister chromatid cohesion, and DNA repair. Prevents the collapse of stalled replication fork in an } \\
\text { ATR-dependent manner and is required for S-phase checkpoint activation }\end{array}$ & [77] \\
\hline BRCA1 & ATR substrate, implicated in the activation of the G2/M checkpoint, homologous recombination, and DSB repair & [78] \\
\hline FANCD2 & $\begin{array}{l}\text { Component of the Fanconi anemia (FA) pathway, phosphorylated by ATR. Plays a role not only in HR- } \\
\text { dependent replication recovery, but also in regulating CFSs stability }\end{array}$ & [79] \\
\hline Polymerase $\eta$ & $\begin{array}{l}\text { Involved in DNA synthesis of complex sequences, like repetitive and secondary structure that impede replication } \\
\text { performing, the so-called 'by-pass' function }\end{array}$ & {$[80]$} \\
\hline Rev3 & Catalytic subunit of Pol $\zeta$ that is required for maintaining fragile site stability in human cells & {$[81]$} \\
\hline Polymerase $\kappa$ & $\begin{array}{l}\text { Involved in DNA synthesis of complex sequences, like repetitive and secondary structure that impede replication } \\
\text { performing }\end{array}$ & {$[82]$} \\
\hline WRN & $\begin{array}{l}\text { RecQ helicase regulated in an ATR and ATM-dependent manner, which prevents DSBs formation at perturbed } \\
\text { forks after replication stress. Promotes stability of arrested RFs and their efficient restart }\end{array}$ & [83] \\
\hline BLM & $\begin{array}{l}\text { RecQ helicase contributing to restarting stalled forks through unwinding DNA structures and/or homologous } \\
\text { recombination, to maintenance of pyrimidine pools balance, regulation of fork speed and decatenation of } \\
\text { UFBs at CFSs }\end{array}$ & {$[49,50]$} \\
\hline RECQ1 & Member of the RecQ family of DNA helicases. Promotes fork recovery and repair & [84] \\
\hline $\begin{array}{l}\text { Topoisomerase I } \\
\text { and II }\end{array}$ & $\begin{array}{l}\text { Alleviate DNA secondary structures during replication by cleavage and re-ligation. Can facilitate oncogenic } \\
\text { rearrangements at induced CFSs }\end{array}$ & {$[85]$} \\
\hline MUS81-EME1 & $\begin{array}{l}\text { Endonuclease involved in resolving HJ-dependent replication intermediates. Required for fork repair and } \\
\text { resolving UFBs }\end{array}$ & {$[41,50]$} \\
\hline $\mathrm{PICH}$ & $\mathrm{PICH}$ (Plk1 interacting checkpoint) is a helicase/translocase involved in resolving UFBs in mitosis & [49] \\
\hline $\begin{array}{l}\text { SNM1B/ } \\
\text { APOLLO }\end{array}$ & $\begin{array}{l}\text { A nuclease component of the FA pathway involved in homology-directed repair. Also facilitates DNA } \\
\text { localization of FANCD2 and BRCA1 }\end{array}$ & [86] \\
\hline Rad51 & Component of the HR pathway involved in DSB repair and HJ mediated RF restart & [47] \\
\hline DNA-PKcs & NHEJ pathway component & [47] \\
\hline Ligase IV & NHEJ pathway component & [47] \\
\hline
\end{tabular}

also in regulating CFSs stability (Table 1) (also reviewed in [31]). Similarly, activation of BRCA1 and other DSB repair proteins like RAD51 have also been found to be vital for maintaining CFSs stability (Table 1) [46]. Apart from HR the non-homologous end join pathway is also essential for chromosomal stability at these sites [47]. Specifically, by knocking down Rad51, DNA-PKcs, or Ligase IV, a significantly increased expression of CFSs under RS has been demonstrated. Notably, MDC1 and $\gamma$-H2AX foci were formed and co-localized with those of Rad51 and DNA-PKcs, while $\gamma$-H2AX and phospho-DNA-PKcs foci localized at expressed FSs on metaphase chromosomes.

Other components implicated in resolving replication over specific CFSs region include specialized polymerases (Table 1) [48]. These polymerases, like DNA polymerase eta (Pol $\eta$ ), mainly deal with DNA synthesis of complex sequences, like repetitive and secondary structures that impede replication, by performing the so-called 'by-pass' function. Depletion of these specialized polymerases has been shown to lead to persistence of unreplicated CFSs in mitosis. Various helicases/translocases have been proposed to promote fork restart at CFSs in non-redundant ways, like the BLM, WRN, and RECQ1 through Holliday junctionmediated fork remodeling that is independent of DSB formation (Table 1) [41]. Their main purpose seems to be resetting of structural intermediates arising from $\mathrm{HR}$ as well as unwinding of DNA secondary structures, in order to facilitate replication fork restart. Alternatively, nucleases, such as the structural endonuclease MUS81-EME1 and the FA pathway nuclease SNM1B/APOLLO, are responsible 
for DSB-mediated fork restart and/or elimination of permanently collapsed forks by cleavage of replication intermediates and consequent DNA synthesis (Table 1) [41].

Many of the above-described factors have been shown to stabilize CFSs during S-phase replication. Nevertheless, recent observations have shown that under RS, non-fully replicated or interlinked DNA at CFSs may escape $S$ and G2-M checkpoints and enter mitosis (reviewed in [13, 49, 50]). Attempts to segregate these intermediates lead to sister chromatid entanglement followed by non-disjunction, ultimately leading to formation of ultra-fine bridges (UFBs) in anaphase cells. UFBs are defined by FANCD2/ FANCI FA proteins binding to their edges, while BLM and PICH (Plk1-interacting checkpoint helicase) attach along the bridge. These persistent replication intermediates have been shown to be processed by the MUS81-EME1 nuclease in early M-phase, possibly with the help of ERCC1, to provide a controlled production of DNA breaks, aiming to allow undisturbed disjunction of sister chromatids. In case of failure, UFBs are formed as mentioned during anaphase. At this stage, BLM helicase and PICH translocase assisted by topoisomerase IIIa (TOPIIIa) and the BLM-associated proteins RMI1/2 function as a second line of defense by decatenating these structures and permitting chromatid segregation [50]. If unresolved UFBs still persist, they will eventually lead to chromosome miss-segregation by uneven distribution of DNA between the daughter cells and micronuclei formation. The transmitted errors at CFSs will be shielded in 53BP1 nuclear bodies in the emerging G1daughter cells and possibly replicated in the S-phase by high-fidelity polymerases. These results pose a new light on CFSs cleavage, and led to the proposal that apart from being detrimental in initiating genomic instability, it can also serve as a mechanism for controlled production of DNA breaks that rather maintain than compromise genome integrity.

Several questions though emerge from this model that has been established with extrinsic factors (chemical inhibitors) that induce RS. How does this model apply and/ or differentiate pre-malignant cells that are known to undergo OIRS? Which of the two types of damage, MUS81-EME1 cleavage or the decatenation inability, confers to the cancer-associated genome instability? A tempting but speculative model is that during premalignant stages, MUS81-EME1 cleavage activity is probably aberrantly increased, leading to a high frequency of DSBs, particularly at CFSs. This could be mediated by the active oncogenes that are present at such stages [2] and which in turn increase the activity of CDKs that regulate MUS81EME1 expression [50]. As long as the checkpoints and their p53 effector are intact, the damage is repaired or the antitumor barriers of apoptosis and senescence eliminate such cells [2]. A similar scenario regarding gross genome damage due to decatenation inability may apply. Notably, it has been recently shown that under moderate RS, CFSs breaks can escape from efficient ATR checkpoint surveillance, leading to mitotic tolerance of such aberrations [44]. Such a pool of cells could undergo selection for loss of checkpoint function(s) and eventually accumulate DNA damage, probably through both MUS81-EME1 processing and chromatid non-disjunctions, provided that they are compatible with survival. Eventually, progression to full malignancy will ensue. This scenario fully concurs with our previous findings showing a prevalence of CFSs breakage along with the presence of UFBs and micronuclei in U2OS cells experiencing OIRS due to sustained expression of the replication licensing factor (RLF) Cdt1 [51]. Importantly, clones of these cells that "escaped" from the antitumor barriers, after prolonged Cdt1 expression, acquired a highly invasive potential. In a paradoxical way, this recently described model of deliberate CFSs controlled breakage to protect genome integrity of cells, may apply to malignant cells in the sense that it allows them to survive at the expense of genome integrity. Further expanding on this model, an emerging question concerns the effect exerted from the CFSs' instability on the various elements like genes and non-coding RNAs that are located within them.

\section{Functional elements in fragile sites}

Several major publications arising from the ENCODE project [10] have underlined the importance of non-coding DNA. Non-coding regions of the genome have been found to participate in biochemical reactions with regulatory potential, such as transcription factor binding, epigenetic modifications, or long-distance interactions. Numerous functions have been attributed to non-coding RNA, including the expanding and best understood family of microRNAs (miRs) that are involved in post-transcriptional regulation of messenger RNA [52]. As a result of this progress, CFSs content may be now understood at a finer scale and the implications of CFS breakage will have to be reexamined carefully.

Fragile sites and cancer-associated genes

While available data point to an overlap between genes and CFSs [5], there is only one report showing that CFSs are denser in protein coding genes, with their distribution among fragile versus non-fragile regions varying among the chromosomes [7]. At the same time, a systematic review for the density of genes present within these genome areas is not available. To address this question, we retrieved a list of 327 genes participating in pathways in 
cancer from the Kyoto Encyclopedia of Genes and Genomes (KEGG) ${ }^{1}$ and investigated their association with both cytogenetically and molecularly mapped CFSs. We found that 110 cancer-related genes (33.6\% of all cancer-related genes) are located within CFSs (Table 2). Based on this, the density of cancer-related genes in a cytogenetically defined CFS compared to the rest of the genome is $37.2 \%$ higher (Fig. 2a).

\section{Fragile sites and microRNA genes}

According to an early study, miRs are particularly frequent in CFSs [6]. Out of the 186 miRs known at the time, 35 were found in, or very close $(<3 \mathrm{Mb})$ to, CFSs, occurring at a density (number of miRs per length) that was estimated to be approximately $9 \%$ higher than in non-FSs. A newer analysis has found approximately $33.8 \%$ of $715 \mathrm{miRs}$ within CFSs, corresponding to a relative $50 \%$ (26-85\%) higher density in regard to non-FSs, but the relation seems to vary between chromosomes [7] with some, like chromosome 16 and 19, having many more fragile than nonfragile miRAs, and others, like chromosome 14, having a lower incidence of miRNAs in fragile regions. Given that the number of known miRs has more than doubled since then, we have repeated this analysis with the recent version of miRBase (v20, [53]) and have found 686 miRs out of $1,871(36.7 \%)$ within cytogenetically defined fragile sites (Table 2) (corresponding incidence in molecularly mapped CFSs is shown in Table 3). Thus, the relative density of miR in cytogenetically defined CFSs is $57 \%$ higher than in the rest of the genome (Fig. 2a; Table 2). Specific pertinent examples include tumor suppressors like hsa-mir-34a in FRA1A and oncomirs like hsa-mir-21 in FRA17B. In addition, more than $50 \%$ of microRNAs seem to be clustered in relatively short regions, up to $50 \mathrm{~kb}$, often containing multiple miR isoforms belonging to the same family [54]. When mapped, approximately $28 \%$ of miR clusters overlap with known FSs. Rearrangements within these regions can disrupt multiple miRs in a single hit and produce complex phenotypic changes.

Fragile sites and regions with regulatory potential

Other DNA elements, such as regions with regulatory potential, may also be contained or overlap with CFSs. As an example, CTCF binding sites from ENCODE ChIP-seq are distributed throughout the genome. CTCF is a critical "weaver" of chromatin structure and function, and can provide an anchor point for nucleosome positioning [55]. Indirectly, CTCF can influence the accessibility of chromatin and plays diverse roles in chromatin insulation, gene

\footnotetext{
${ }^{1}$ http://www.genome.jp/kegg/pathway/hsa/hsa05200.html.
}

regulation, imprinting, intra/interchromosomal interactions, nuclear compartmentalization, and alternative splicing [56, 57]. In some cases, distal fragments bound by CTCF have been found to mediate long-range interactions by loop formation and could modulate transcription at distant sites [58]. We examined the percentage of all potential CTCF binding sites within molecularly mapped CFSs and found that this ranges between 2.76 and $3.20 \%$ in different cell lines (Table 4). Relative to the total length of fragile segments, this corresponds to an $18 \%$ (10-25\%)-fold increase in the number of potential CTCF binding sites (Fig. 2a). Although it is impossible to know whether CTCF binding at these sites exerts a meaningful effect, its presence seems in accordance with the observation that many CFSs are gene-rich. Even more, CFSs rearrangements could influence gene expression further away on the same chromosome.

Fragile sites and histone modifications

Epigenetic modifications, such as histone methylation and acetylation, can also take place within FS. It appears that $\mathrm{H} 3 \mathrm{~K} 9 / 14$ hypoacetylation is a global feature of CFSs in a lymphoblastoid cell line [9] and could impede replication progression. Several enzymes modify key histone residues with relatively high specificity and regulate, indirectly, transcription, repair, and replication. Indeed, histone modifications vary significantly between cell types and are well correlated with transcription levels in the ENCODE data (Figure 2 in [10]), especially for H3K79me2, H3K9ac, H3K4me3, and H3K27ac. Histone 3 lysine 27 acetylation (H3K27ac) co-localizes with active enhancers [59] and regions with open chromatin structure and could play a role in protecting against replication-transcription collisions and R-loop formation. Intriguingly, $\mathrm{H} 3 \mathrm{~K} 27 \mathrm{ac}$ varies between cell types and CFSs (Fig. 2b, c). The average ChIP-seq acetylation signal and the number of signal peaks (data not shown) within cytogenetic CFSs are slightly lower than the corresponding chromosome mean in K562 cells, but higher in HUVEC cells and equivocal for other cell types. Such variability may explain the plasticity of CFSs and their differential expression between individuals, cell types, and culture conditions.

Histone 3 lysine 4 trimethylation is also associated with active promoters [60] and correlates well with transcription in the ENCODE data [10]. It appears that H3K4me3 may also contribute to the DNA damage response and repair of DSBs in yeast cells [61], mediating cellular responses to genotoxic stresses, and interacting with the human tumor suppressor ING1, which is required for DNA repair and apoptotic activities [62]. A recent study of ERFSs [9] has shown that replication stall, as identified by anti-replication 


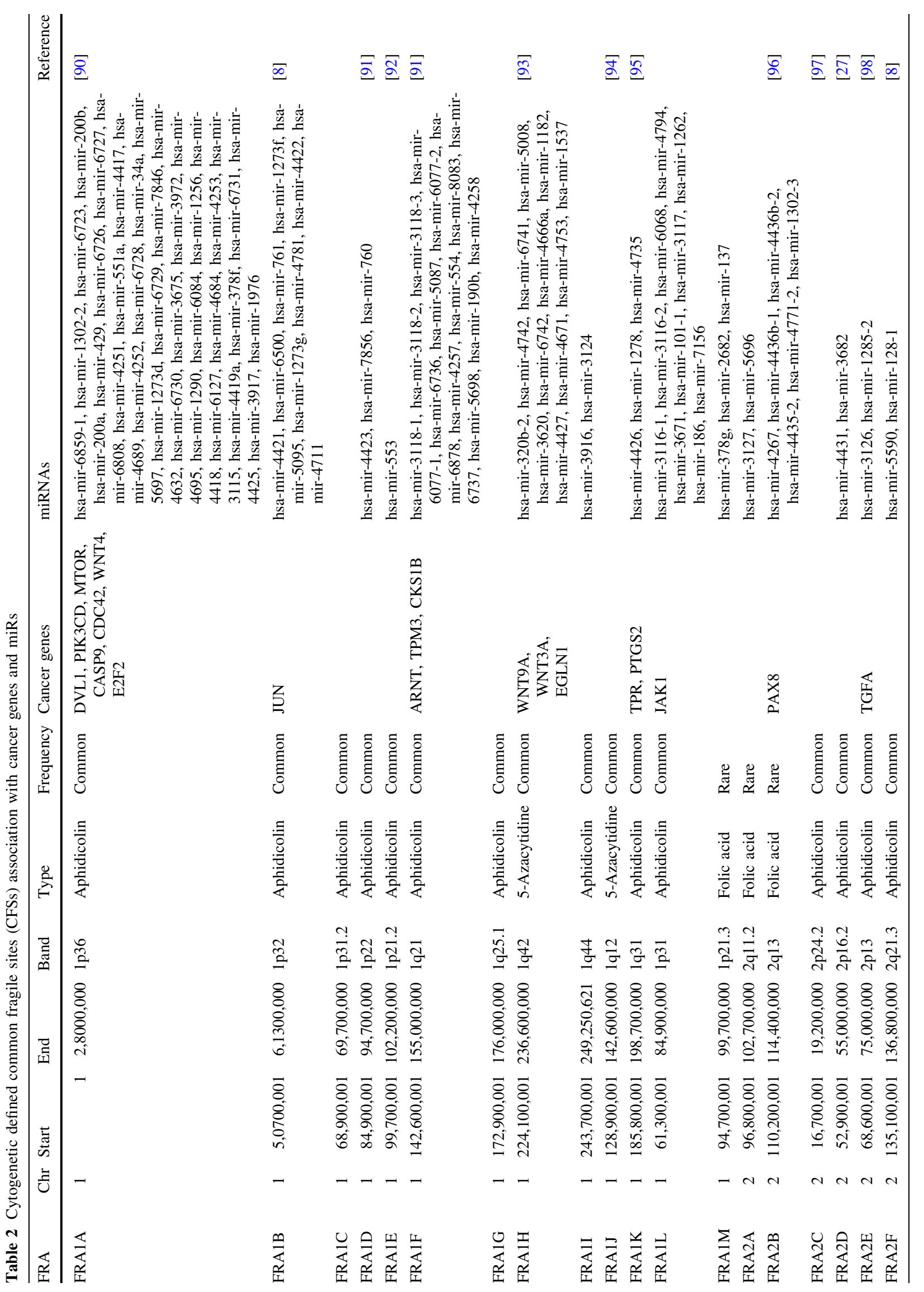




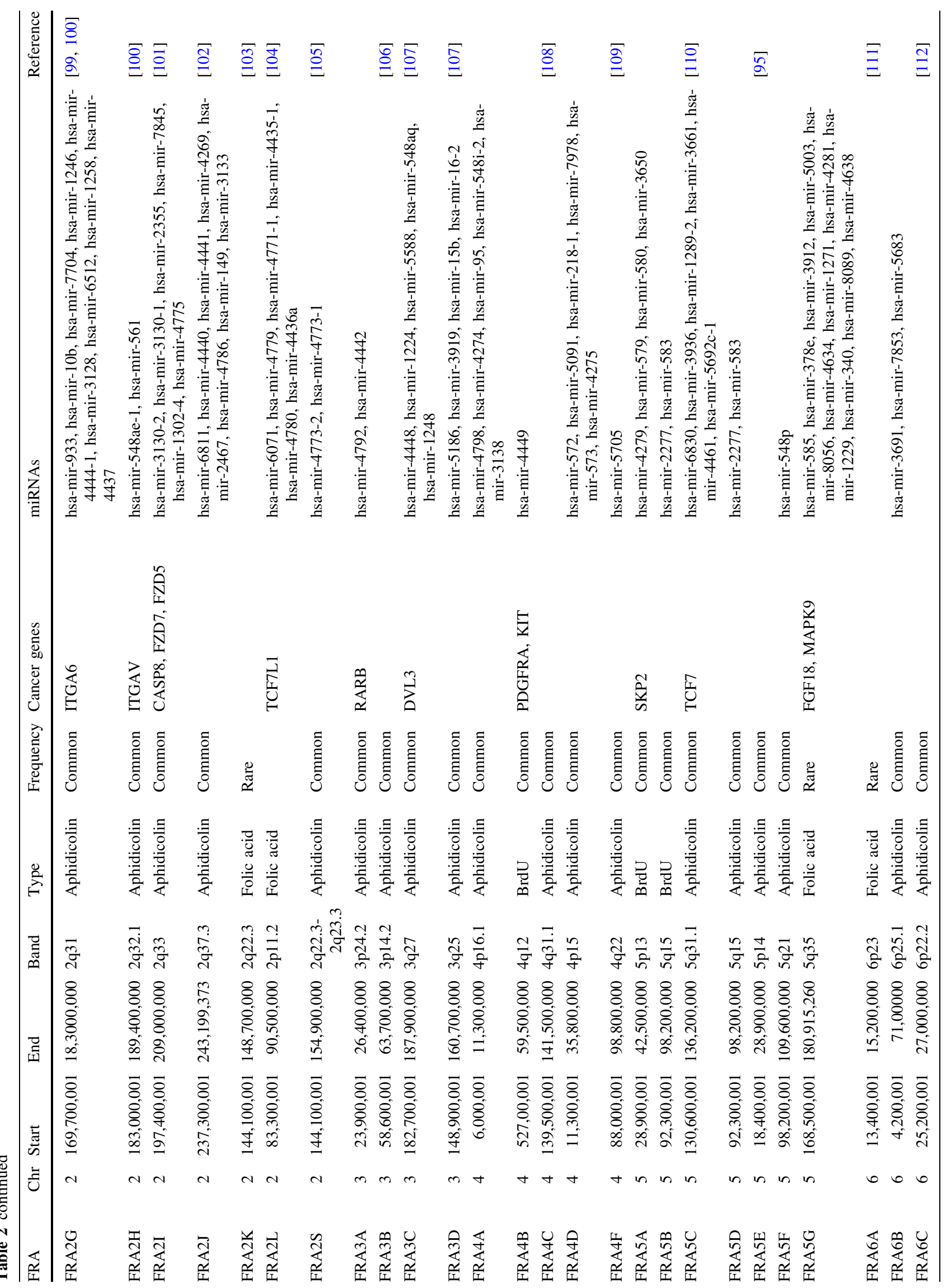




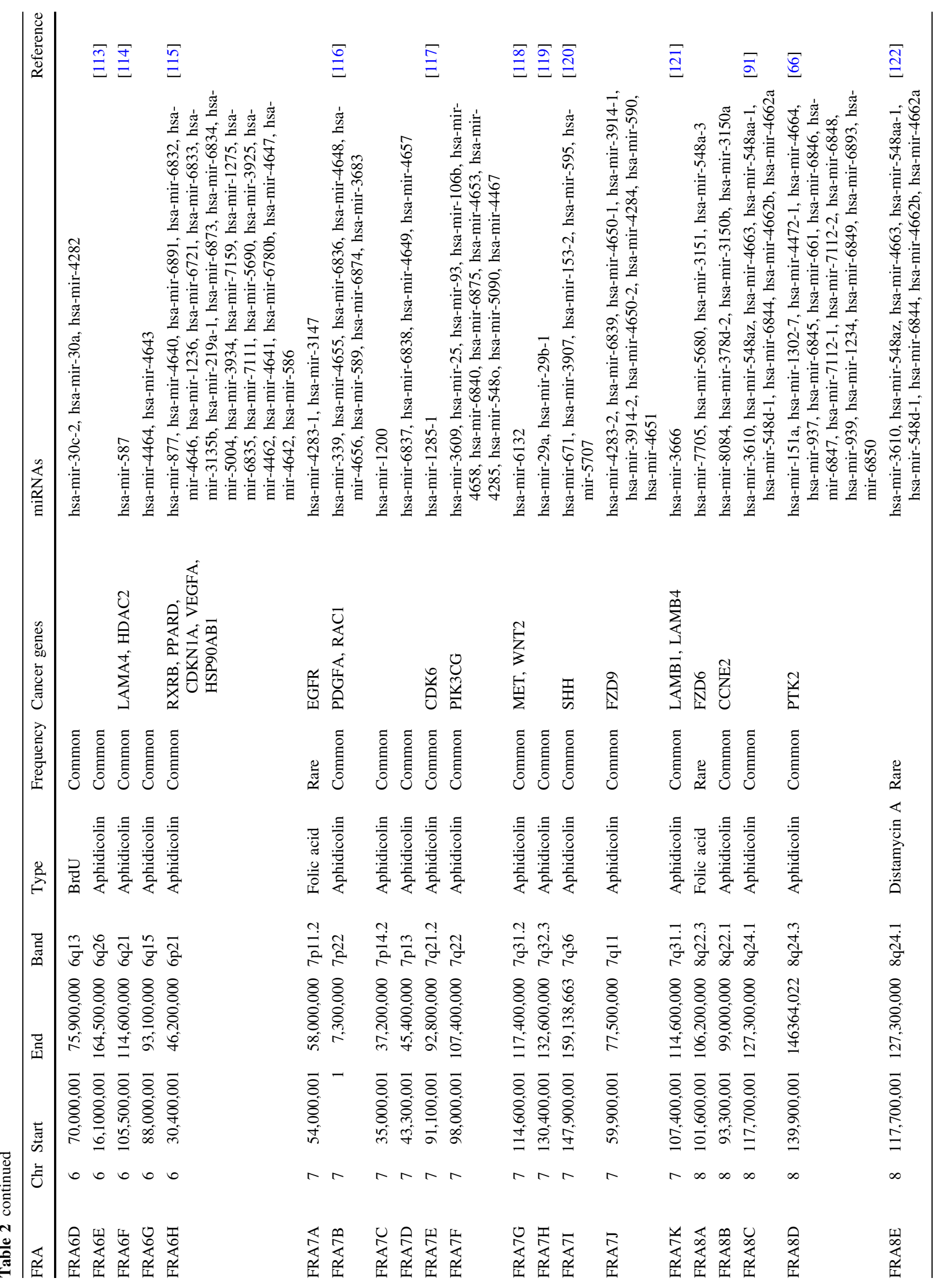




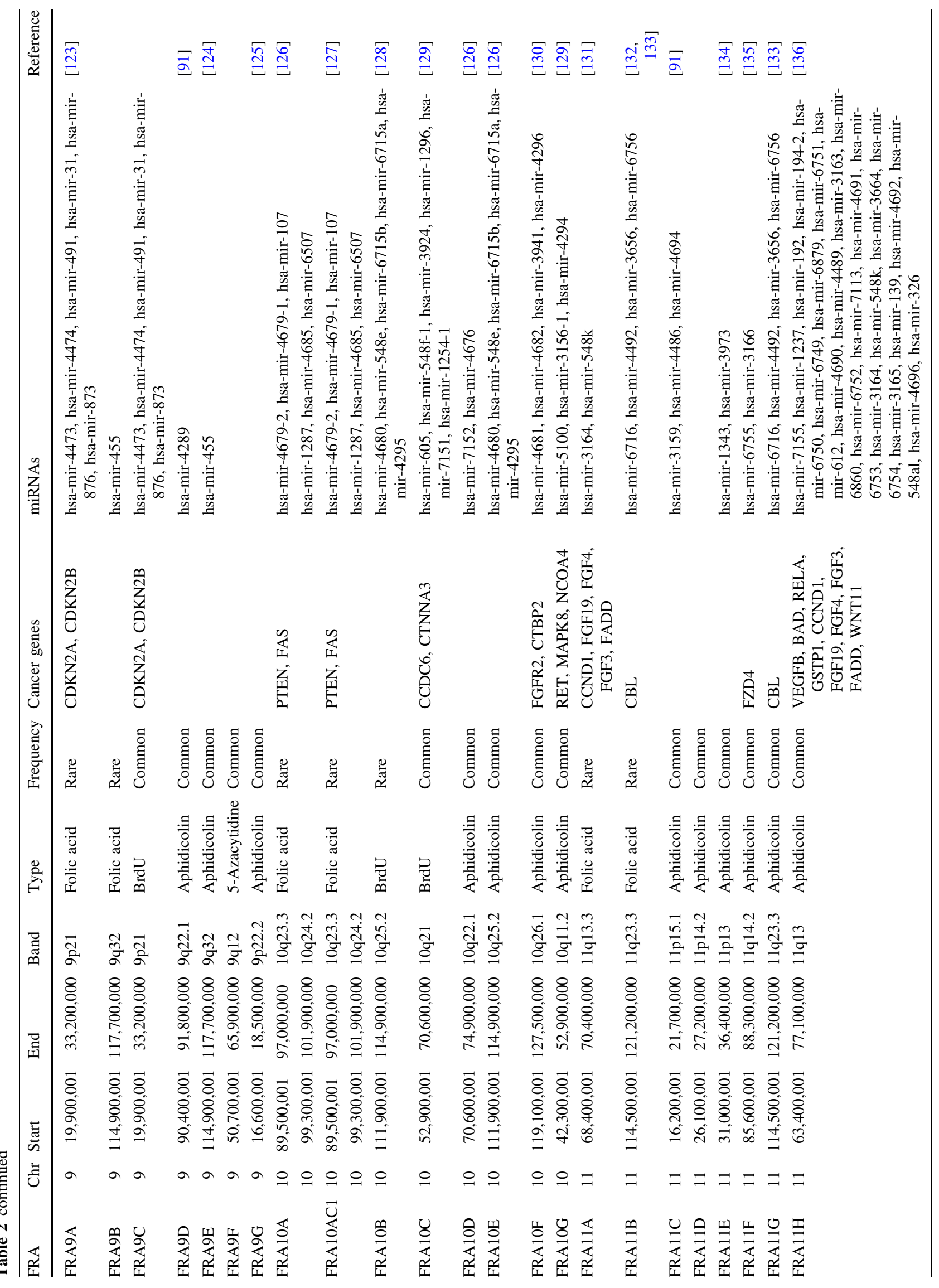




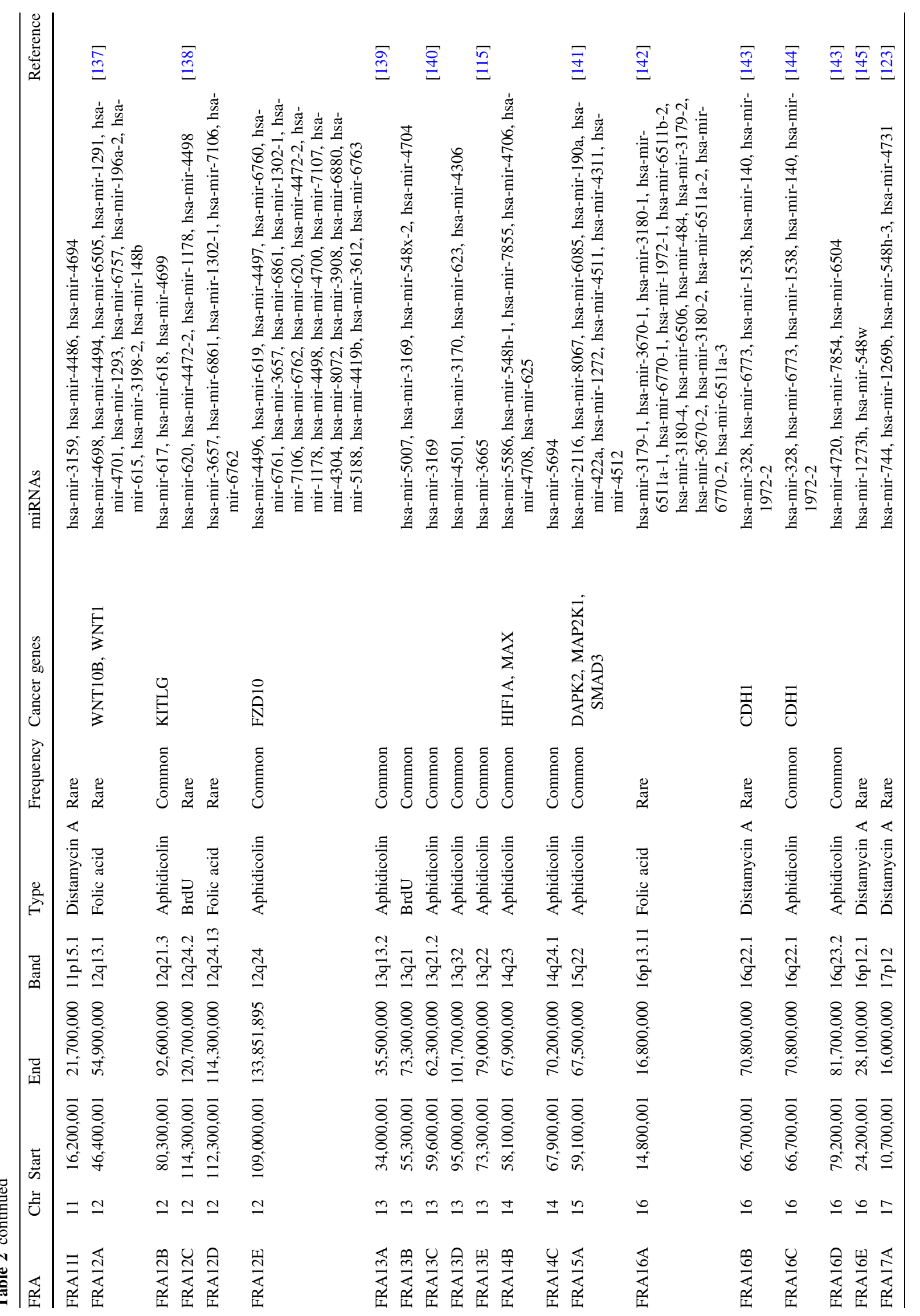




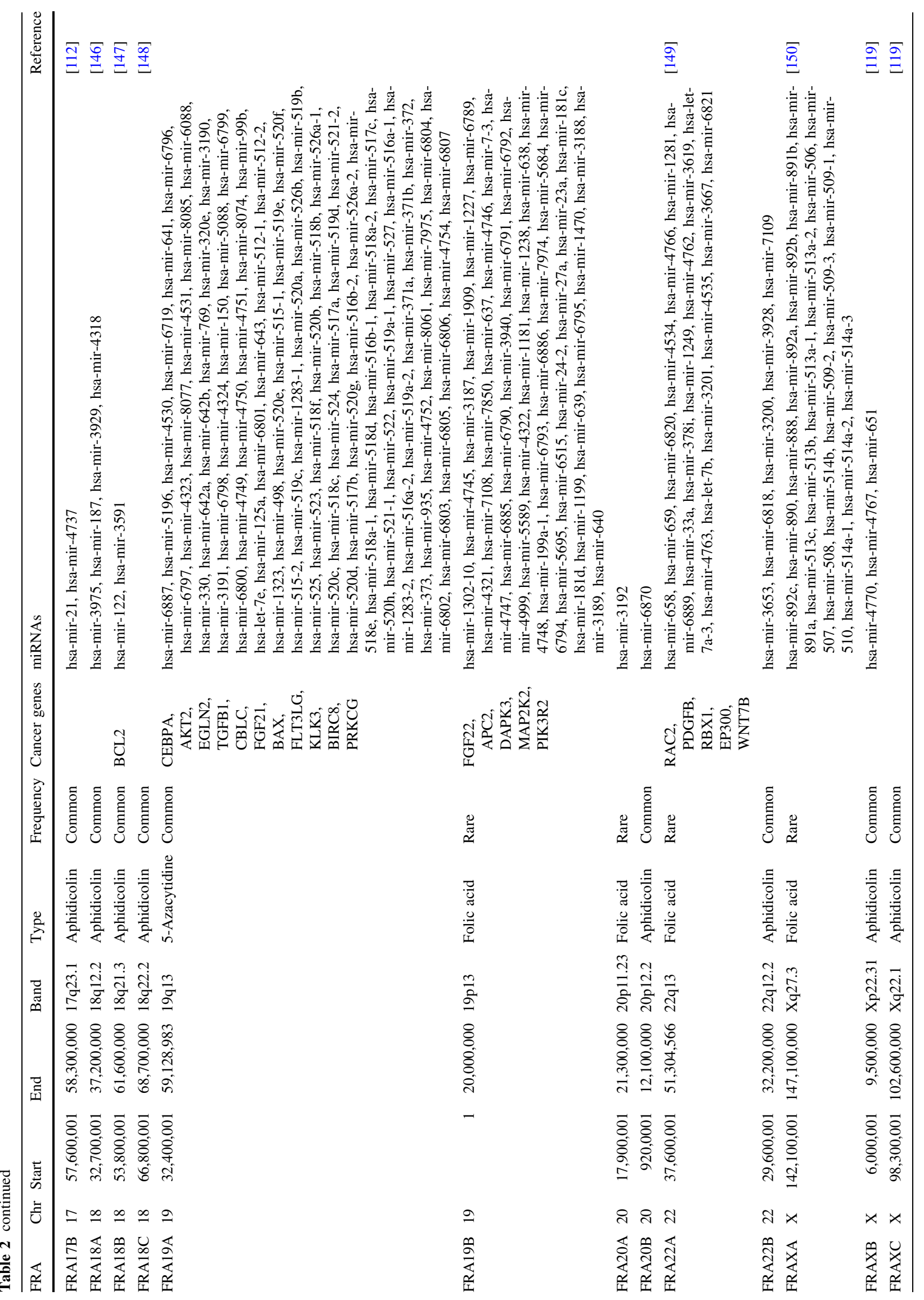




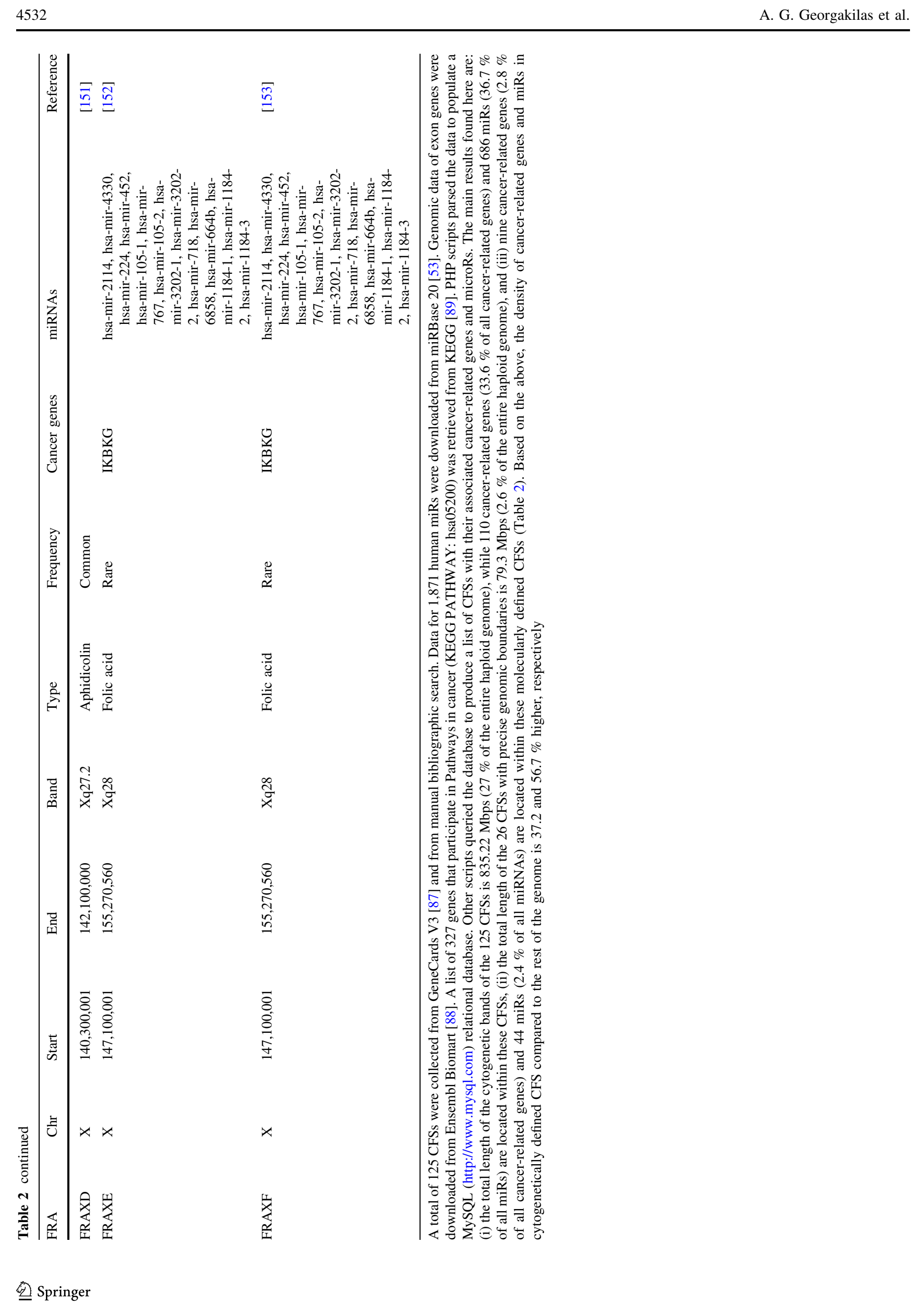


(a)

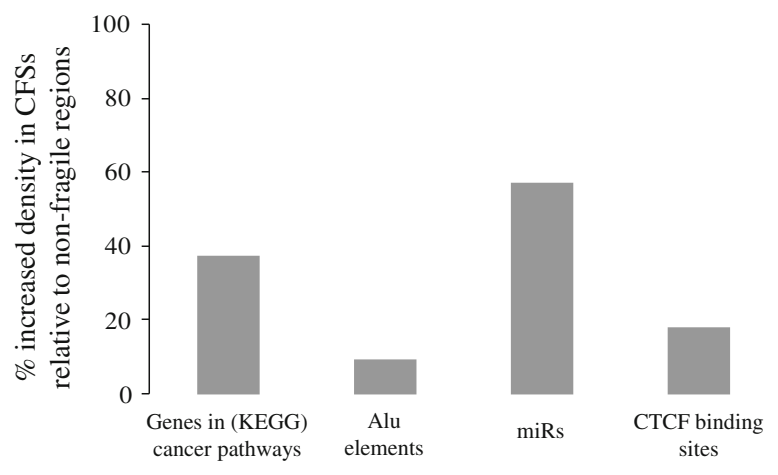

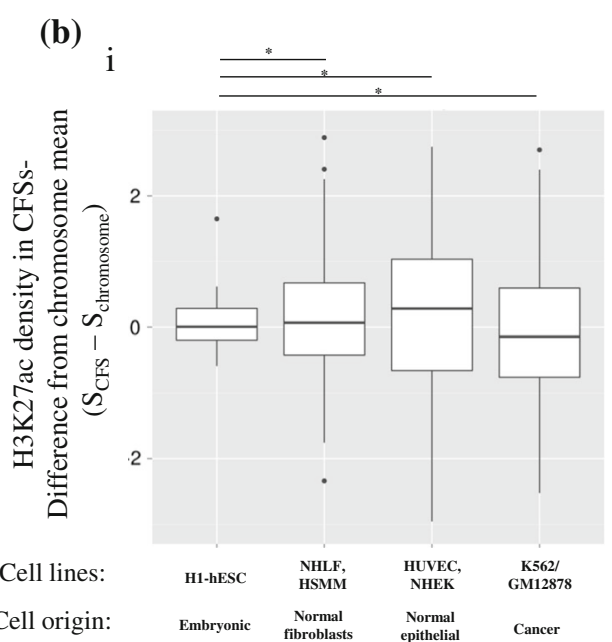

Fig. 2 Frequency of cancer-related genes, repetitive elements, miRs, binding elements, and histone marks in CFSs. a CFSs exhibit a higher density of cancer-related genes (obtained from Kyoto Encyclopedia of Genes and Genomes), Alu repetitive elements [19], miRs, and the CTCF binding element relative to non-fragile regions. b CFSs exhibit a differential density of the histone marks (i) Histone 3 lysine 27 acetylation (H3K27ac) and (ii) Histone 3 lysine 4 trimethylation (H3K4me3), relative to non-fragile regions that is cell type origindependent (data concerning histone modifications derived from ChIPseq experiments belonging to the ENCODE project were downloaded from the UCSC server (http://hgdownload.cse.ucsc.edu/goldenPath/ hg19/encodeDCC/wgEncodeRegMarkH3k4me3/, http://hgdownload. cse.ucsc.edu/goldenPath/hg19/encodeDCC/wgEncodeRegMarkH3k2 $7 \mathrm{ac} /$ ). Specifically, we obtained bigWig files for $\mathrm{H} 3 \mathrm{k} 4 \mathrm{me} 3$ and H3k27ac modifications in the GM12878, H1-hesc, HSMM, HUVEC, K562, NHEK, and NHLF cell types. Information concerning regions of interest was extracted with the bigWigSummary utility, also available from the UCSC server. Specifically, the average signal was

protein A ChIP, preferentially co-localizes with $\mathrm{H} 3 \mathrm{~K} 4 \mathrm{me} 3$ (see supplemental figure 1 in [16]). Although cytogenetically defined CFSs as a whole do not show a large deviation from the mean, some sites in particular, like FRA3B and FRA16D, seem to be on average poor in H3K4me3 while others, like FRA2E, FRA3C, and FRA7D seem to be on average rich in $\mathrm{H} 3 \mathrm{~K} 4 \mathrm{me} 3$ (Fig. 2c). When the cell lines employed were grouped according to their

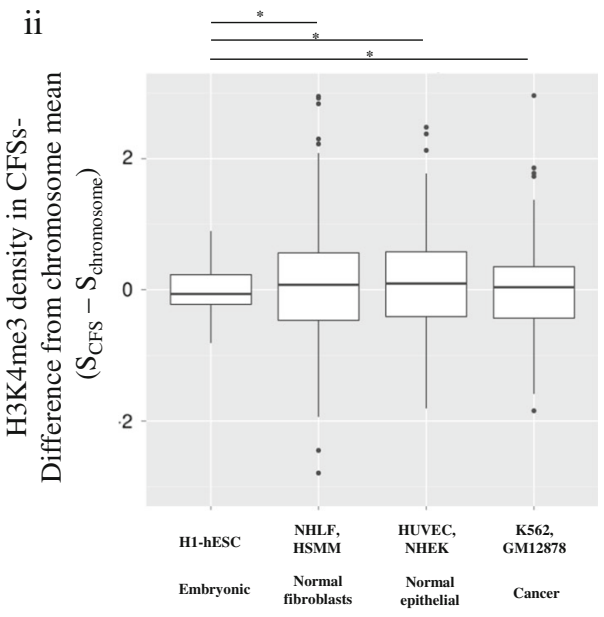

calculated for every chromosome in every cell line by repeatedly invoking: bigWigSummary-type = mean "bigwigfile" chrN start end. Similarly, the average signal was calculated for cytogenetically and molecularly mapped fragile sites. For every defined fragile site, the mean histone modification signal of the corresponding chromosome was subtracted from the mean signal of the fragile region. Signal difference from mean for site $i=\operatorname{mean}\left(\mathrm{FS}_{i}\right)$ - mean(chromosome $_{\mathrm{FS} i}$ ). The chromosome means varied within each cell type (data not shown), as did the histone modifications between cell types) ( $S$ histone signal). c Frequency of histone marks per CFSs. Each CFS exhibits a differential density of the histone marks. (i) Histone 3 lysine 4 trimethylation $(\mathrm{H} 3 \mathrm{~K} 4 \mathrm{me} 3)$ and (ii) Histone 3 lysine 27 acetylation (H3K27ac), relative to non-fragile regions averaged over all cell types presented in Fig. 2 (using the data generated for Fig. 2b, we also plotted a boxplot for individual cytogenetically defined CFSs in all 7 cell lines mentioned above with respect to $\mathrm{H} 3 \mathrm{~K} 4 \mathrm{me} 3$ and H3K27ac. Significant heterogeneity between CFSs can be observed)

origin (cancerous versus embryonic versus normal epithelial versus normal mesenchymal), a pattern regarding the density of the H3K27ac and $\mathrm{H} 3 \mathrm{~K} 4 \mathrm{me} 3$ within CFSs relative to non-fragile sites could be discerned (Fig. 2b). Cancer and embryonic cells (K562, GM12878, H1-hESC) displayed lower signals of $\mathrm{H} 3 \mathrm{~K} 27 \mathrm{ac}$ and $\mathrm{H} 3 \mathrm{~K} 4 \mathrm{me} 3$ relative to the non-fragile regions, whereas a significantly different distribution was noticed in the other cell line groups 

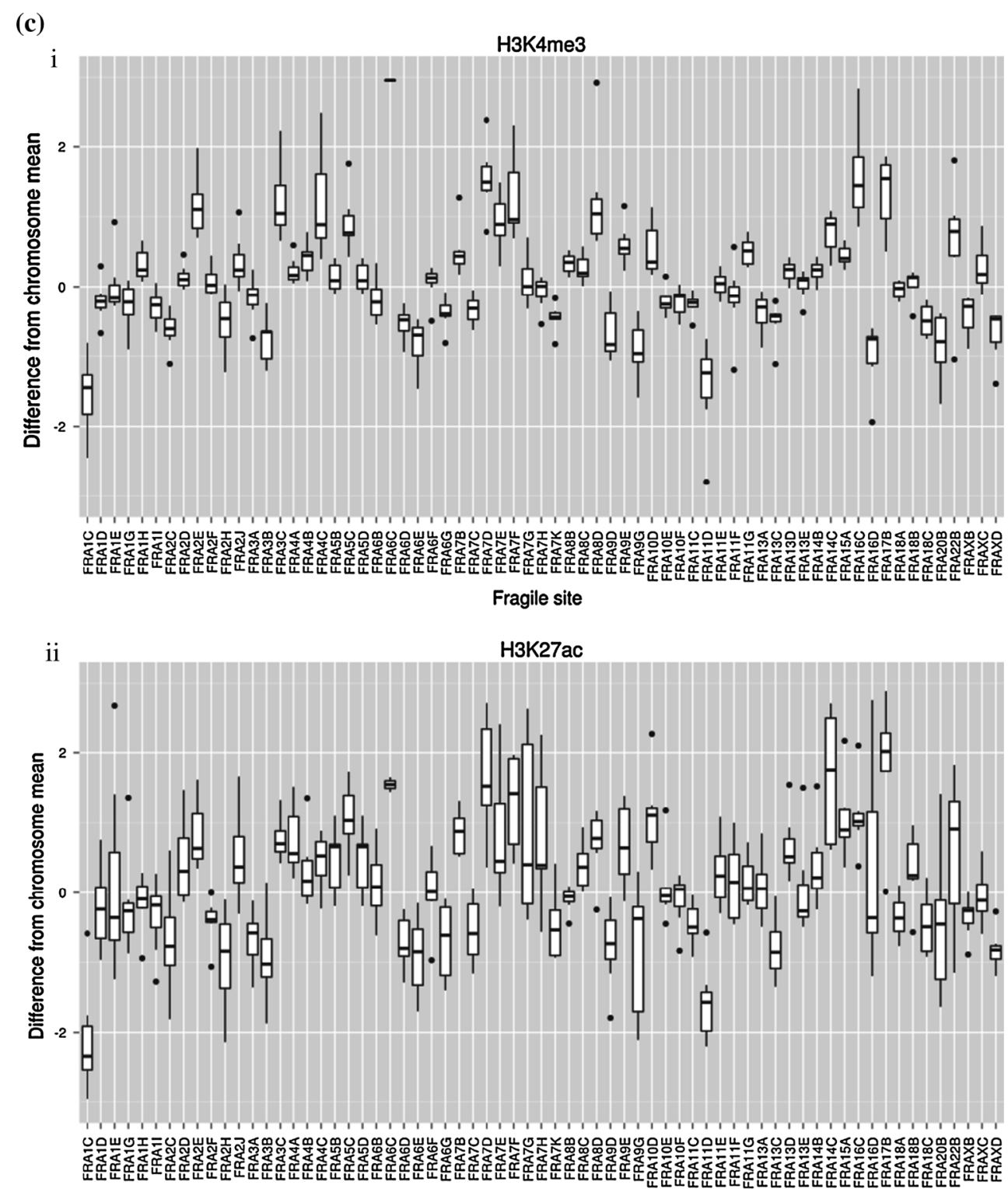

Fragile site

Fig. 2 continued

( $p<0.001$, ANOVA). Despite the small number of cell lines examined, a possible functional link between histone modifications and the other elements (genes, non-coding RNAs, regulatory sequences) positioned within the CFS cannot be excluded (Fig. 1). This potential interplay may be even more complex during carcinogenesis. Oncogenes may distress this functional cross-talk by altering the epigenome of a particular region. As an example, oncogenic Cdc6 was shown to act as "molecular switch" at certain tumor-suppressor loci by regulating CTCF binding. The latter led to suppression of the genes encoded and simultaneous firing of adjacent dormant origins. If such a scenario takes place within CFS that are rich in CTCF sites
(Fig. 2a), and depending on the cellular context, the density and timing of firing origins can be altered affecting replication dynamics [56, 57].

Our current understanding of CFSs is traditionally based on a static mapping, often cytogenetic and imprecise, which cannot fully capture the interaction of non-coding DNA, regulatory elements, and histone modifications with vulnerability to RS. Even though the current CFS mapping successfully predicts response to extrinsic stress and OIRS, a more accurate model of fragility will eventually have to integrate experimental data at the nucleotide resolution with other non-coding elements. This is an intriguing area for further study. 


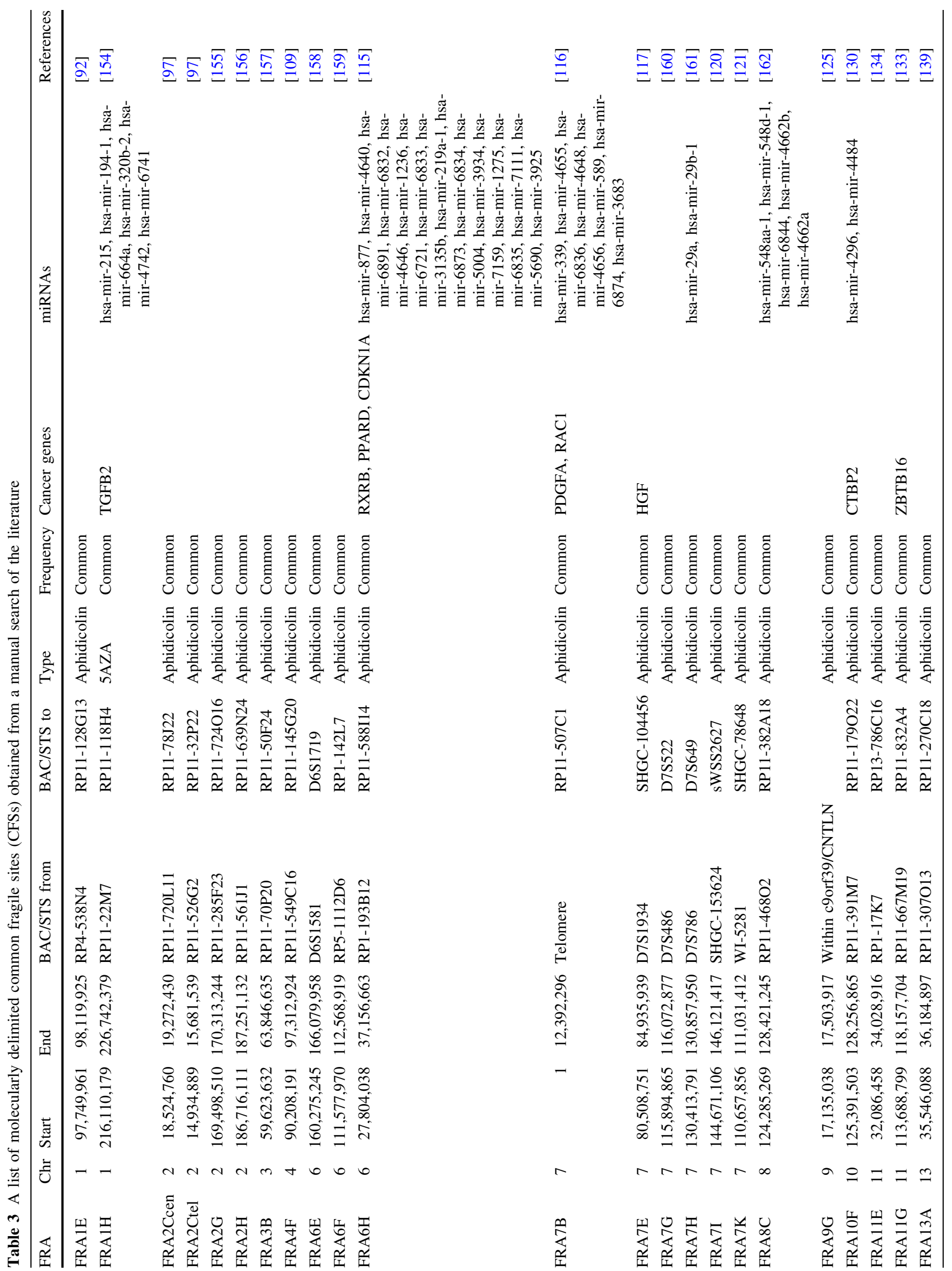




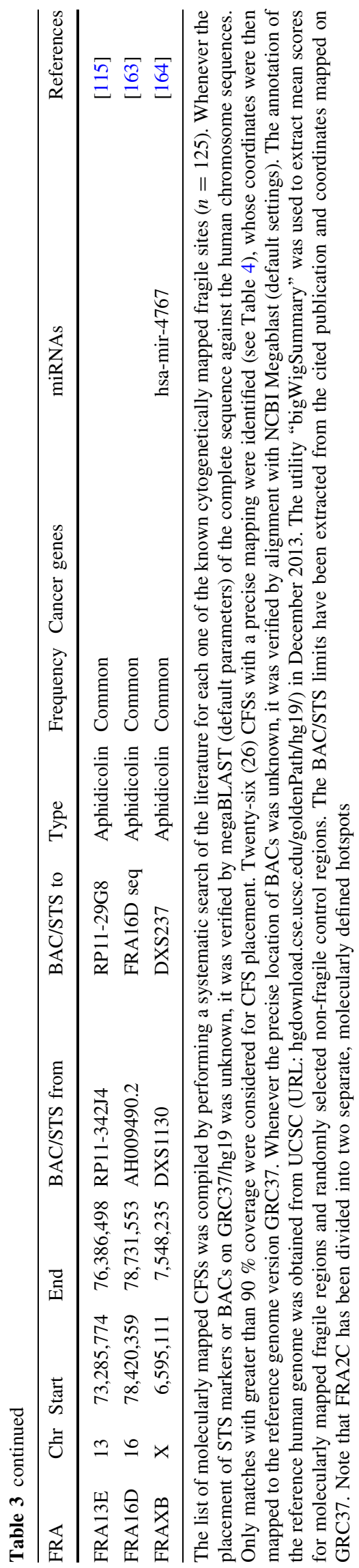

\section{Fragile sites in carcinogenesis}

Extending the concept of CFSs in carcinogenesis has been a subject of active research since the discovery of an association between cancer breakpoints and FSs [63]. Overall, it appears that CFSs are generally sensitive to innate RS occurring naturally in various tumors and cell lines [64]. Multiple clusters of homozygous deletions, usually small, have been detected over known CFSs in an exhaustive survey of cancer genomes but their expression profile is variable [65]. For example, FRA2F, FRA3B, FRA4F, FRA5H, and FRA16D were most affected while others, like FRA2B and FRA4B, were least affected. Recurrent alterations have been identified in FRA3B and FRA16D in several cancer types, leading to further investigation of the FHIT and WWOX genes, respectively, in mouse models (see K. Huebner and R. Aqeilan chapters in this issue). Fragile sites FRA10C and FRA10G may be involved in the formation of the oncogenic RET/PTC rearrangement in papillary thyroid carcinoma [15]. Specifically, in RET/PTCl, the FRA10G-localized RET is rearranged with the FRA10C-localized tumor suppressor gene $C C D C 6$, while in RET/PTC3 it is rearranged with $\mathrm{NCO} 4$ that is located in FRA10G. In a similar manner, the MYC oncogene is flanked by CFSs FRA8C and FRA8D, that may facilitate adjacent integration of HPV18 [66] or MYC amplification [67]. Viral DNA integration in the genome of a host cell can lead to cancer development and CFSs provide preferential hotspots for this [68]. Particularly, HPV16 E6 and E7 oncogenic products have been shown to induce replication stress and DSBs in the host cell. This occurs preferentially at CFSs allowing viral genome integration at these sites [68].

Despite the abundance of CFS breaks in cancer, it would be inappropriate to assume that alterations of genes residing within CFSs always confer a clonal advantage in cancer development [65] without evidence of selection or at least convincing causative models. Clearly, breakage probability (passenger alterations) as a consequence of fragility and clonal selection (driver alterations) in cancer development are two separate phenomena that should not be confused.

Nevertheless, the impact of CFS instability in cancer should not be easily dismissed or oversimplified. CFSs breakpoints have been detected in preneoplastic lesions in human and mouse models [4, 19] well before the emergence of the malignant phenotype. Briefly, exposure of xenografted normal human skin to growth factors preferentially induces CFS instability. Similarly, hyperplastic mouse urothelium from HRAS transgenic mice showed numerous copy number alterations in fragile areas. CFS instability is an early manifestation and can be attributed to experimentally controlled, oncogene-induced stress in these studies, in a way that more closely resembles 
Table 4 Data from ENCODE [10] with respect to molecularly mapped common fragile sites (CFSs) from Table 3

\begin{tabular}{|c|c|c|c|c|c|}
\hline Name & CTCF bs (count) & CTCF bs $(\%)$ & CTCF bs/kbp & $\mathrm{H} 3 \mathrm{~K} 27 \mathrm{ac}$ & 99-way cons. score \\
\hline FRA1E & 97 & 0.002 & 0.261 & 1.32 & 0.133 \\
\hline FRA1H & 17,338 & 0.372 & 1.631 & 3.07 & - \\
\hline FRA2Ctel & 700 & 0.015 & 0.938 & 2.53 & 0.071 \\
\hline FRA2Ccen & 1,108 & 0.024 & 1.486 & 1.56 & 0.111 \\
\hline FRA2G & 1,501 & 0.032 & 1.698 & 4.22 & 0.114 \\
\hline FRA2H & 132 & 0.003 & 0.255 & 1.44 & 0.103 \\
\hline FRA3B & 4,156 & 0.089 & 0.982 & 1.57 & 0.105 \\
\hline FRA4F & 4,765 & 0.102 & 0.671 & 1.63 & 0.085 \\
\hline FRA6H & 33,735 & 0.724 & 3.607 & 8.14 & 0.12 \\
\hline FRA6F & 2,104 & 0.045 & 2.123 & 2.93 & 0.126 \\
\hline FRA6E & 6,274 & 0.135 & 1.081 & 2.47 & 0.062 \\
\hline FRA7B & 23,331 & 0.5 & 1.907 & 3.13 & - \\
\hline FRA7E & 4,253 & 0.091 & 0.961 & 1.6 & 0.082 \\
\hline FRA7K & 265 & 0.006 & 0.709 & 2.56 & 0.097 \\
\hline FRA7G & 265 & 0.006 & 1.489 & 2.46 & 0.098 \\
\hline FRA7H & 1,458 & 0.031 & 3.283 & 4.38 & 0.089 \\
\hline FRA7I & 435 & 0.009 & 0.3 & 1.98 & 0.065 \\
\hline FRA8C & 8,599 & 0.184 & 2.079 & 3.26 & 0.082 \\
\hline FRA9G & 168 & 0.004 & 0.455 & 1.2 & 0.142 \\
\hline FRA10F & 5,878 & 0.126 & 2.051 & 2.57 & 0.071 \\
\hline FRA11E & 4,494 & 0.096 & 2.314 & 4.05 & 0.123 \\
\hline FRA11G & 9,545 & 0.205 & 2.136 & 2.57 & 0.126 \\
\hline FRA13A & 193 & 0.004 & 0.302 & 1.23 & 0.108 \\
\hline FRA13E & 2,950 & 0.063 & 0.951 & 1.78 & 0.104 \\
\hline FRA16D & 378 & 0.008 & 1.215 & 1.87 & 0.118 \\
\hline FRAXB & 718 & 0.015 & 0.753 & 1.54 & 0.056 \\
\hline
\end{tabular}

CTCF binding sites, studied in 89 cell lines, are shown respectively as absolute counts, with respect to the total number of CTCF binding sites in the whole genome and as a frequency per kb. Average H3k27 acetylation scores from ChIP-seq analysis of the K562 cell line have been calculated for each fragile site. Average conservation score between human and 99 vertebrates was obtained from the UCSC browser (http:// genome.ucsc.edu/cgi-bin/hgTrackUi? db=hg19\&g=cons100way). We compiled a list of molecularly mapped CFSs by performing a systematic search of the literature for each one of the known cytogenetically mapped CFSs $(n=125)$. Twenty-six CFSs with a precise mapping were identified (see Table 3), and their coordinates were then mapped to the reference genome version GRC37. Whenever the precise location of BACs was unknown, it was verified by alignment with NCBI Megablast (default settings). The annotation of the reference human genome was obtained from UCSC (URL: hgdownload.cse.ucsc.edu/goldenPath/hg19/) in December 2013. The utility "bigWigSummary" was used to extract mean scores for molecularly mapped fragile regions and randomly selected non-fragile control regions

carcinogenesis than APH-induced stress. Therefore, it could be argued that CFS alterations are frequent in cancer, as described above [65], not just because of a higher breakage probability but also because of an earlier involvement, even before the complete deregulation of the cellular machinery.

Furthermore, any double-strand break can have dire consequences, such as the initiation of a breakage-fusionbridge cycle, especially when subtelomeric and peri-centromeric CFSs are disrupted simultaneously [69]. Through this mechanism, CFS breaks can amplify oncogenes, delete tumor suppressors or, most importantly, initiate persistent chromosomal instability. Massive accumulation of localized chromosomal rearrangements in a single time-point, termed chromothripsis (literally: shattering of the chromosome) and chromoanasynthesis, has recently been identified in several cancer types [70]. Indirect evidence suggests that CFSs may have an important role in this process [71] by stalling the RF, favoring RF collapse and, in extreme cases, chromosome pulverization leading to clustering of chromosomal breaks [13]. Indeed, chromosome fragmentation distal to the CFS has been observed under the microscope in some cases [71] and could be a triggering factor for chromothripsis. On the other hand, multi-step, recurrent CFS alterations could be difficult to discriminate from single-step rearrangements, rendering the identification of chromothripsis even more difficult. In that scenario, CFS stability and localization is an important 
parameter in the bioinformatic algorithms that are applied to define and model such cancer rearrangements. In addition, CFSs can contribute to the clustered shuttering of the chromosomes also during the process of premature chromatin condensation (PCC) [72, 73] in which interphase chromosomes or late replicating chromosome zones like CFS or extranuclear bodies micronuclei are 'induced' to condensation by various mitotic factors [74]. This reveals more possibilities for CFSs to act as contributors to GI through chromosome breakage. An interesting scenario suggested that the G2-M mammalian checkpoint can fail to delay mitotic onset as it may not be sensitive enough to detect a few remaining long-replicating forks, thus allowing chromatin condensation of late replicating CFS regions, resulting in multiple DNA breaks [26, 44].

\section{CFSs as "functional" units: a new perception}

Common fragile sites have long been considered vulnerable breakage sites in the genome in response to RS from extrinsic factors. Their fragility has also been associated with GI in cancer development. As we have previously shown, CFSs are preferentially affected from the earliest precancerous lesions, in response to OIRS [2, 4]. In the current work, we first performed a review on the heterogeneity and fragility mechanisms affecting these sites. Next, by applying bioinformatic tools and exploiting available information in various databases, like the KEGG, miRbase, and ENCODE, we show a prevalence of various cancer-related genes, miRs, binding elements, and histone modifications in CFSs (Figs. 1, 3). The presence of such a wide spectrum of coding and non-coding elements changes the view on CFSs content and their nature itself. Given that CFSs are altered from the earliest stages in cancer, their impact on cancer development may be more profound than simply participating in the emergence of GI. On one hand, cancer-related genes and miRs may be affected from such early precancerous stages, therefore possibly exerting a strong pressure for malignant progression (Fig. 3). On the other hand, this pressure is also reinforced by alterations and imbalances in the binding elements and histone patterns, respectively, in the CFSs. Furthermore, collectively, all these alterations may further affect in an "avalanche" mode not only the stability of the CFSs, but overall of the genome (Figs. 1, 3). Therefore, as the anti-tumor barriers are gradually overwhelmed, this avalanche effect may function in a positive feedback mode to promote cancer. An important question that emerges is why CFSs are not selected for elimination from the genome, but are rather conserved features in mammals? A tempting but speculative answer is that by locating a set of important coding and non-coding elements in regions that replicate late and/or with delay and thus are prone to instability, they may function as alarm sensors scattered throughout the genome in various chromosomes, to signify detrimental effects from the RS on the cell. As long as the mammalian checkpoints and repair mechanisms are not compromised, cells can monitor and protect their genome and functional integrity through such a dynamic interaction. Nevertheless, this imposes the risk that if the checkpoints and the antitumor barriers gradually fail, tumor promotion ensues (Fig. 3). As we were able to examine only a small subset of binding elements and histone modifications from the ENCODE and the miRbase is constantly expanding, in the future more in-depth studies are required to obtain a comprehensive picture of CFSs and on their role in cancer. Overall, CFSs may not be merely structural domains vulnerable only to breakage but highly organized "functional" units that may have deeper biological consequences for the cell when affected.

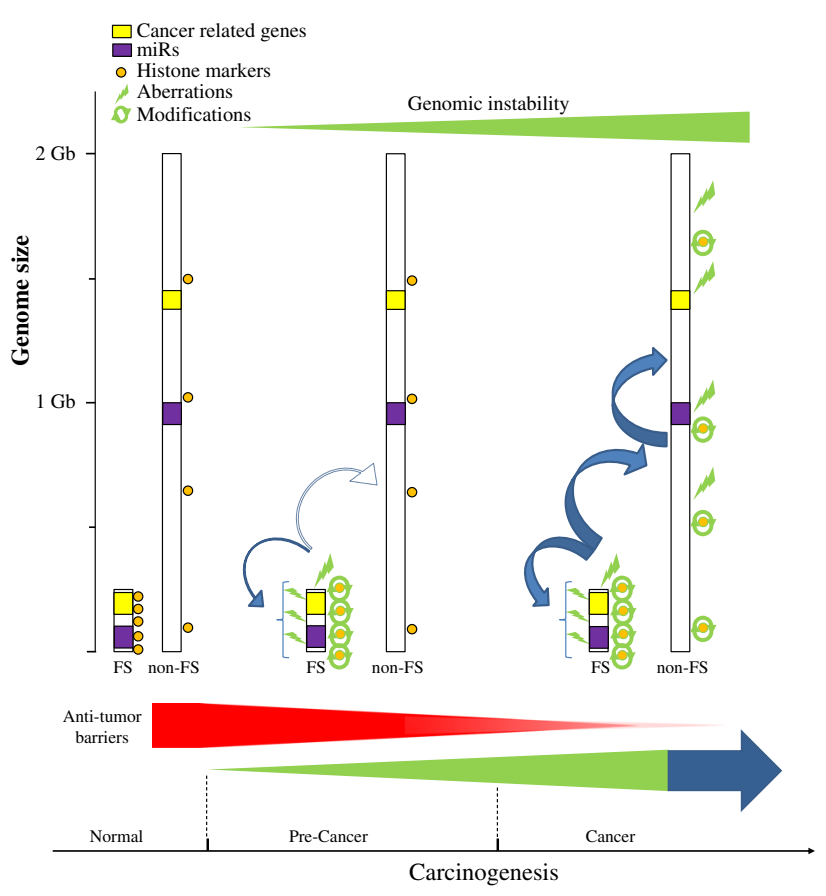

Fig. 3 Model proposing that CFS apart from contributing to GI exert wider biological effects during cancer development. CFSs are preferentially affected from the earliest precancerous lesions, in response to OIRS, conferring to GI. A wide spectrum of coding and non-coding elements are present within CFSs. Cancer-related genes and miRs may be affected from such early precancerous stages, therefore possibly exerting a strong pressure for malignant progression. This pressure is also reinforced by alterations and imbalances in the binding elements and histone patterns, respectively, in the CFSs. Furthermore, collectively, all of these alterations may further affect in an "avalanche" mode not only the stability of the CFSs, but overall of the genome. As the anti-tumor barriers are gradually overwhelmed, this avalanche effect may function in a positive feedback mode to promote cancer 
Acknowledgments Financial support was provided from the European Union's Seventh Framework Programme for research, technological development and demonstration under grant agreement No 284460. Dr. Georgakilas was supported by an EU Marie Curie Reintegration Grant MC-CIG-303514, Greek National funds through the Operational Program 'Educational and Lifelong Learning of the National Strategic Reference Framework (NSRF)-Research Funding Program: THALES (Grant number MIS 379346) and COST Action CM1201 'Biomimetic Radical Chemistry'. Dr A. Kotsinas is a recipient of an Empeirikeion Foundation fellowship.

Conflict of interest All authors have no conflict of interest to declare.

Open Access This article is distributed under the terms of the Creative Commons Attribution License which permits any use, distribution, and reproduction in any medium, provided the original author(s) and the source are credited.

\section{References}

1. Hanahan D, Weinberg RA (2011) Hallmarks of cancer: the next generation. Cell 144(5):646-674. doi:10.1016/j.cell.2011.02.013

2. Halazonetis TD, Gorgoulis VG, Bartek J (2008) An oncogeneinduced DNA damage model for cancer development. Sci Mar 319:1352-1355

3. Negrini S, Gorgoulis VG, Halazonetis TD (2010) Genomic instability-an evolving hallmark of cancer. Nat Rev Mol Cell Biol 11:220-228

4. Gorgoulis VG, Vassiliou L-VF, Karakaidos P, Zacharatos P, Kotsinas A, Liloglou T, Venere M, DiTullio RA, Kastrinakis NG, Levy B, Kletsas D, Yoneta A, Herlyn M, Kittas C, Halazonetis TD (2005) Activation of the DNA damage checkpoint and genomic instability in human precancerous lesions. Nature 434(7035):907-913

5. Dereli-Oz A, Versini G, Halazonetis TD (2011) Studies of genomic copy number changes in human cancers reveal signatures of DNA replication stress. Mol Oncol 5(4):308-314. doi:10.1016/j.molonc.2011.05.002

6. Calin GA, Sevignani C, Dumitru CD, Hyslop T, Noch E, Yendamuri S, Shimizu M, Rattan S, Bullrich F, Negrini M, Croce CM (2004) Human microRNA genes are frequently located at fragile sites and genomic regions involved in cancers. Proc Natl Acad Sci USA 101(9):2999-3004. doi:10.1073/pnas. 0307323101

7. Lagana A, Russo F, Sismeiro C, Giugno R, Pulvirenti A, Ferro A (2010) Variability in the incidence of miRNAs and genes in fragile sites and the role of repeats and $\mathrm{CpG}$ islands in the distribution of genetic material. PLoS ONE 5(6):e11166. doi:10. 1371/journal.pone.0011166

8. Smith DI, Zhu Y, McAvoy S, Kuhn R (2006) Common fragile sites, extremely large genes, neural development and cancer. Cancer Lett 232(1):48-57. doi:10.1016/j.canlet.2005.06.049

9. Jiang Y, Lucas I, Young DJ, Davis EM, Karrison T, Rest JS, Le Beau MM (2009) Common fragile sites are characterized by histone hypoacetylation. Hum Mol Genet 18(23):4501-4512. doi: $10.1093 / \mathrm{hmg} / \mathrm{ddp} 410$

10. Encode Project Consortium, Bernstein BE, Birney E, Dunham I, Green ED, Gunter C, Snyder M (2012) An integrated encyclopedia of DNA elements in the human genome. Nature 489(7414):57-74. doi:10.1038/nature11247

11. Sutherland GR, Jacky PB, Baker EG (1984) Heritable fragile sites on human chromosomes. XI. Factors affecting expression of fragile sites at $10 \mathrm{q} 25,16 \mathrm{q} 22$, and $17 \mathrm{p} 12$. Am J Hum Genet 36(1):110-122

12. Glover T, Berger C, Coyle J, Echo B (1984) DNA polymerase alpha inhibition by aphidicolin induces gaps and breaks at common fragile sites in human chromosomes. Hum Genet 67(2):136-142

13. Debatisse M, Le Tallec B, Letessier A, Dutrillaux B, Brison O (2012) Common fragile sites: mechanisms of instability revisited. Trends Genet 28(1):22-32. doi:10.1016/j.tig.2011.10.003

14. Ozeri-Galai E, Bester AC, Kerem B (2012) The complex basis underlying common fragile site instability in cancer. Trends Genet 28(6):295-302

15. Dillon LW, Burrow AA, Wang YH (2010) DNA instability at chromosomal fragile sites in cancer. Curr Genomics 11(5):326-337. doi:10.2174/138920210791616699

16. Barlow JH, Faryabi RB, Callén E, Wong N, Malhowski A, Chen HuaB T, Gutierrez-Cruz G, Sun H-W, McKinnon P, Wright G, Casellas R, Robbiani DavideB F, Staudt L, Fernandez-Capetillo O, Nussenzweig A (2013) Identification of early replicating fragile sites that contribute to genome instability. Cell 152(3):620-632

17. Mortusewicz O, Herr P, Helleday T (2013) Early replication fragile sites: where replication-transcription collisions cause genetic instability. EMBO J 32(4):493-495. doi:10.1038/emboj. 2013.20

18. Le Beau MM, Rassool FV, Neilly ME, Espinosa R 3rd, Glover TW, Smith DI, McKeithan TW (1998) Replication of a common fragile site, FRA3B, occurs late in S phase and is delayed further upon induction: implications for the mechanism of fragile site induction. Hum Mol Genet 7(4):755-761

19. Tsantoulis PK, Kotsinas A, Sfikakis PP, Evangelou K, Sideridou M, Levy B, Mo L, Kittas C, Wu XR, Papavassiliou AG, Gorgoulis VG (2007) Oncogene-induced replication stress preferentially targets common fragile sites in preneoplastic lesions. A genome-wide study. Oncogene 27(23):3256-3264

20. Seo J, Kim K, Chang DY, Kang HB, Shin EC, Kwon J, Choi JK (2013) Genome-wide reorganization of histone H2AX toward particular fragile sites on cell activation. Nucleic Acids Res. doi:10.1093/nar/gkt951

21. Sfeir A, Kosiyatrakul ST, Hockemeyer D, MacRae SL, Karlseder J, Schildkraut CL, de Lange T (2009) Mammalian telomeres resemble fragile sites and require TRF1 for efficient replication. Cell 138(1):90-103. doi:10.1016/j.cell.2009.06.021

22. Murano I, Kuwano A, Kajii T (1989) Fibroblast-specific common fragile sites induced by aphidicolin. Hum Genet 83(1):45-48

23. Le Tallec B, Dutrillaux B, Lachages AM, Millot GA, Brison O, Debatisse M (2011) Molecular profiling of common fragile sites in human fibroblasts. Nat Struct Mol Biol 18:1421-1423

24. Hosseini SA, Horton S, Saldivar JC, Miuma S, Stampfer MR, Heerema NA, Huebner K (2013) Common chromosome fragile sites in human and murine epithelial cells and FHIT/FRA3B loss-induced global genome instability. Genes Chromosomes Cancer 52(11):1017-1029. doi:10.1002/gcc.22097

25. Le Tallec B, Millot GA, Blin ME, Brison O, Dutrillaux B, Debatisse M (2013) Common fragile site profiling in epithelial and erythroid cells reveals that most recurrent cancer deletions lie in fragile sites hosting large genes. Cell Rep 4(3):420-428. doi:10.1016/j.celrep.2013.07.003

26. Letessier A, Millot GA, Koundrioukoff S, Lachages AM, Vogt N, Hansen RS, Malfoy B, Brison O, Debatisse M (2011) Celltype-specific replication initiation programs set fragility of the FRA3B fragile site. Nature 470(7332):120-123. doi:10.1038/ nature 09745

27. Helmrich A, Stout-Weider K, Hermann K, Schrock E, Heiden T (2006) Common fragile sites are conserved features of human 
and mouse chromosomes and relate to large active genes. Genome Res 16(10):1222-1230. doi:10.1101/gr.5335506

28. Elder FF, Robinson TJ (1989) Rodent common fragile sites: are they conserved? Evidence from mouse and rat. Chromosoma 97(6):459-464

29. Raveendranathan M, Chattopadhyay S, Bolon YT, Haworth J, Clarke DJ, Bielinsky AK (2006) Genome-wide replication profiles of S-phase checkpoint mutants reveal fragile sites in yeast. EMBO J 25(15):3627-3639. doi:10.1038/sj.emboj. 7601251

30. Denison SR, Simper RK, Greenbaum IF (2003) How common are common fragile sites in humans: interindividual variation in the distribution of aphidicolin-induced fragile sites. Cytogenet Genome Res 101(1):8-16

31. Durkin SG, Glover TW (2007) Chromosome fragile sites. Annu Rev Genet 41:169-192. doi:10.1146/annurev.genet.41.042007. 165900

32. Franchitto A (2013) Genome instability at common fragile sites: searching for the cause of their instability. Biomed Res Int 2013:730714. doi:10.1155/2013/730714

33. Häsler J, Strub K (2006) Alu elements as regulators of gene expression. Nucleic Acids Res 34(19):5491-5497. doi:10.1093/ nar/gkl706

34. Ostertag EM, Kazazian HH Jr (2001) Biology of mammalian L1 retrotransposons. Annu Rev Genet 35:501-538. doi:10.1146/ annurev.genet.35.102401.091032

35. Helmrich A, Ballarino M, Tora L (2011) Collisions between replication and transcription complexes cause common fragile site instability at the longest human genes. Mol Cell 44(6):966-977. doi:10.1016/j.molcel.2011.10.013

36. Palumbo E, Matricardi L, Tosoni E, Bensimon A, Russo A (2010) Replication dynamics at common fragile site FRA6E. Chromosoma 119(6):575-587. doi:10.1007/s00412-010-0279-4

37. Mulvihill DJ, Wang YH (2004) Two breakpoint clusters at fragile site FRA3B form phased nucleosomes. Genome Res 14(7):1350-1357. doi:10.1101/gr.2304404

38. Kastan MB, Bartek J (2004) Cell-cycle checkpoints and cancer. Nature 432(7015):316-323. doi:10.1038/nature03097

39. Casper AM, Nghiem P, Arlt MF, Glover TW (2002) ATR regulates fragile site stability. Cell 111(6):779-789

40. Ozeri-Galai E, Lebofsky R, Rahat A, Bester AC, Bensimon A, Kerem B (2011) Failure of origin activation in response to fork stalling leads to chromosomal instability at fragile sites. Mol Cell 43(1):122-131. doi:10.1016/j.molcel.2011.05.019

41. Petermann E, Helleday T (2010) Pathways of mammalian replication fork restart. Nat Rev Mol Cell Biol 11(10):683-687. doi: $10.1038 / \mathrm{nrm} 2974$

42. Zhu M, Weiss RS (2007) Increased common fragile site expression, cell proliferation defects, and apoptosis following conditional inactivation of mouse Hus 1 in primary cultured cells. Mol Biol Cell 18(3):1044-1055. doi:10.1091/mbc.E06-100957

43. Focarelli ML, Soza S, Mannini L, Paulis M, Montecucco A, Musio A (2009) Claspin inhibition leads to fragile site expression. Genes Chromosomes Cancer 48(12):1083-1090. doi:10. $1002 / g c c .20710$

44. Koundrioukoff S, Carignon S, Techer H, Letessier A, Brison O, Debatisse M (2013) Stepwise activation of the ATR signaling pathway upon increasing replication stress impacts fragile site integrity. PLoS Genet 9(7):e1003643. doi:10.1371/journal.pgen. 1003643

45. Glover TW, Stein CK (1987) Induction of sister chromatid exchanges at common fragile sites. Am J Hum Genet 41(5):882-890

46. Arlt MF, Durkin SG, Ragland RL, Glover TW (2006) Common fragile sites as targets for chromosome rearrangements. DNA
Repair (Amst) 5(9-10):1126-1135. doi:10.1016/j.dnarep.2006. 05.010

47. Schwartz M, Zlotorynski E, Goldberg M, Ozeri E, Rahat A, le Sage C, Chen BP, Chen DJ, Agami R, Kerem B (2005) Homologous recombination and nonhomologous end-joining repair pathways regulate fragile site stability. Genes Dev 19(22):2715-2726. doi:10.1101/gad.340905

48. Bergoglio V, Boyer AS, Walsh E, Naim V, Legube G, Lee MY, Rey L, Rosselli F, Cazaux C, Eckert KA, Hoffmann JS (2013) DNA synthesis by Pol eta promotes fragile site stability by preventing under-replicated DNA in mitosis. J Cell Biol 201(3):395-408. doi:10.1083/jcb.201207066

49. Pellicioli A, Muzi-Falconi M (2013) A blooming resolvase at chromosomal fragile sites. Nat Cell Biol 15(8):883-885. doi:10. 1038/ncb2812

50. Minocherhomji S, Hickson ID (2013) Structure-specific endonucleases: guardians of fragile site stability. Trends Cell Biol. doi:10.1016/j.tcb.2013.11.007

51. Liontos M, Koutsami M, Sideridou M, Evangelou K, Kletsas D, Levy B, Kotsinas A, Nahum O, Zoumpourlis V, Kouloukoussa M, Lygerou Z, Taraviras S, Kittas C, Bartkova J, Papavassiliou AG, Bartek J, Halazonetis TD, Gorgoulis VG (2007) Deregulated overexpression of hCdt 1 and hCdc 6 promotes malignant behavior. Cancer Res 67(22):10899-10909. doi:10.1158/00085472.CAN-07-2837

52. Chen K, Rajewsky N (2007) The evolution of gene regulation by transcription factors and microRNAs. Nat Rev Genet 8(2):93-103. doi: $10.1038 / \operatorname{nrg} 1990$

53. Kozomara A, Griffiths-Jones S (2011) miRBase: integrating microRNA annotation and deep-sequencing data. Nucleic Acids Res 39(Database issue):D152-D157. doi:10.1093/nar/gkq1027

54. Mathelier A, Carbone A (2013) Large scale chromosomal mapping of human microRNA structural clusters. Nucleic Acids Res 41(8):4392-4408. doi:10.1093/nar/gkt112

55. Fu Y, Sinha M, Peterson CL, Weng Z (2008) The insulator binding protein CTCF positions 20 nucleosomes around its binding sites across the human genome. PLoS Genet 4(7):e1000138. doi:10.1371/journal.pgen. 1000138

56. Holwerda SJ, de Laat W (2013) CTCF: the protein, the binding partners, the binding sites and their chromatin loops. Philos Trans R Soc Lond B Biol Sci 368(1620):20120369. doi:10.1098/ rstb.2012.0369

57. Sideridou M, Zakopoulou R, Evangelou K, Liontos M, Kotsinas A, Rampakakis E, Gagos S, Kahata K, Grabusic K, Gkouskou K, Trougakos IP, Kolettas E, Georgakilas AG, Volarevic S, Eliopoulos AG, Zannis-Hadjopoulos M, Moustakas A, Gorgoulis VG (2011) Cdc6 expression represses E-cadherin transcription and activates adjacent replication origins. J Cell Biol 195(7):1123-1140. doi:10.1083/jcb.201108121

58. Sanyal A, Lajoie BR, Jain G, Dekker J (2012) The long-range interaction landscape of gene promoters. Nature 489(7414):109-113. doi:10.1038/nature11279

59. Creyghton MP, Cheng AW, Welstead GG, Kooistra T, Carey BW, Steine EJ, Hanna J, Lodato MA, Frampton GM, Sharp PA, Boyer LA, Young RA, Jaenisch R (2010) Histone H3K27ac separates active from poised enhancers and predicts developmental state. Proc Natl Acad Sci USA 107(50):21931-21936. doi:10.1073/pnas.1016071107

60. Guenther MG, Levine SS, Boyer LA, Jaenisch R, Young RA (2007) A chromatin landmark and transcription initiation at most promoters in human cells. Cell 130(1):77-88. doi:10.1016/ j.cell.2007.05.042

61. Faucher D, Wellinger RJ (2010) Methylated H3K4, a transcription-associated histone modification, is involved in the DNA damage response pathway. PLoS Genet 6(8):e1001082. doi:10.1371/journal.pgen.1001082 
62. Peña PV, Hom RA, Hung T, Lin H, Kuo AJ, Wong RPC, Subach OM, Champagne KS, Zhao R, Verkhusha VV, Li G, Gozani O, Kutateladze TG (2008) Histone H3K4me3 binding is required for the DNA repair and apoptotic activities of ING1 tumor suppressor. J Mol Biol 380(2):303-312. doi:10.1016/j. jmb.2008.04.061

63. Hecht F, Glover TW (1984) Cancer chromosome breakpoints and common fragile sites induced by aphidicolin. Cancer Genet Cytogenet 13(2):185-188

64. DiTullio RA Jr, Mochan TA, Venere M, Bartkova J, Sehested M, Bartek J, Halazonetis TD (2002) 53BP1 functions in an ATM-dependent checkpoint pathway that is constitutively activated in human cancer. Nat Cell Biol 4(12):998-1002. doi:10. 1038/ncb892

65. Bignell GR, Greenman CD, Davies H, Butler AP, Edkins S, Andrews JM, Buck G, Chen L, Beare D, Latimer C, Widaa S, Hinton J, Fahey C, Fu B, Swamy S, Dalgliesh GL, Teh BT, Deloukas P, Yang F, Campbell PJ, Futreal PA, Stratton MR (2010) Signatures of mutation and selection in the cancer genome. Nature 463(7283):893-898. doi:10.1038/nature08768

66. Ferber MJ, Eilers P, Schuuring E, Fenton JA, Fleuren GJ, Kenter G, Szuhai K, Smith DI, Raap AK, Brink AA (2004) Positioning of cervical carcinoma and Burkitt lymphoma translocation breakpoints with respect to the human papillomavirus integration cluster in FRA8C at 8q24.13. Cancer Genet Cytogenet 154(1):1-9. doi:10.1016/j.cancergencyto.2004.01.028

67. Gibaud A, Vogt N, Brison O, Debatisse M, Malfoy B (2013) Characterization at nucleotide resolution of the homogeneously staining region sites of insertion in two cancer cell lines. Nucleic Acids Res 41(17):8210-8219. doi:10.1093/nar/gkt566

68. Thorland EC, Myers SL, Gostout BS, Smith DI (2003) Common fragile sites are preferential targets for HPV16 integrations in cervical tumors. Oncogene 22(8):1225-1237. doi:10.1038/sj. onc. 1206170

69. Coquelle A, Pipiras E, Toledo F, Buttin G, Debatisse M (1997) Expression of fragile sites triggers intrachromosomal mammalian gene amplification and sets boundaries to early amplicons. Cell 89(2):215-225

70. Stephens PJ, Greenman CD, Fu B, Yang F, Bignell GR, Mudie LJ, Pleasance ED, Lau KW, Beare D, Stebbings LA, McLaren S, Lin ML, McBride DJ, Varela I, Nik-Zainal S, Leroy C, Jia M, Menzies A, Butler AP, Teague JW, Quail MA, Burton J, Swerdlow H, Carter NP, Morsberger LA, Iacobuzio-Donahue C, Follows GA, Green AR, Flanagan AM, Stratton MR, Futreal PA, Campbell PJ (2011) Massive genomic rearrangement acquired in a single catastrophic event during cancer development. Cell 144(1):27-40. doi:10.1016/j.cell.2010.11.055

71. Mackinnon RN, Campbell LJ (2013) Chromothripsis under the microscope: a cytogenetic perspective of two cases of AML with catastrophic chromosome rearrangement. Cancer Genet 206(6):238-251. doi:10.1016/j.cancergen.2013.05.021

72. El Achkar E, Gerbault-Seureau M, Muleris M, Dutrillaux B, Debatisse M (2005) Premature condensation induces breaks at the interface of early and late replicating chromosome bands bearing common fragile sites. Proc Natl Acad Sci USA 102(50):18069-18074. doi:10.1073/pnas.0506497102

73. Hashash N, Johnson AL, Cha RS (2012) Topoisomerase II- and condensin-dependent breakage of $\mathrm{MEC}^{A T R}$-sensitive fragile sites occurs independently of spindle tension, anaphase, or cytokinesis. PLoS Genet 8(10):e1002978. doi:10.1371/journal. pgen. 1002978

74. Ravi M, Nivedita K, Pai GM (2013) Chromatin condensation dynamics and implications of induced premature chromosome condensation. Biochimie 95(2):124-133. doi:10.1016/j.biochi. 2012.10.001
75. Casper AM, Durkin SG, Arlt MF, Glover TW (2004) Chromosomal instability at common fragile sites in Seckel syndrome. Am J Hum Genet 75(4):654-660. doi:10.1086/422701

76. Ozeri-Galai E, Schwartz M, Rahat A, Kerem B (2008) Interplay between ATM and ATR in the regulation of common fragile site stability. Oncogene 27(15):2109-2117. doi:10.1038/sj.onc. 1210849

77. Musio A, Montagna C, Mariani T, Tilenni M, Focarelli ML, Brait L, Indino E, Benedetti PA, Chessa L, Albertini A, Ried T, Vezzoni P (2005) SMC1 involvement in fragile site expression. Hum Mol Genet 14(4):525-533. doi:10.1093/hmg/ddi049

78. Arlt MF, Xu B, Durkin SG, Casper AM, Kastan MB, Glover TW (2004) BRCA1 is required for common-fragile-site stability via its G2/M checkpoint function. Mol Cell Biol 24(15):6701-6709. doi:10.1128/MCB.24.15.6701-6709.2004

79. Howlett NG, Taniguchi T, Durkin SG, D'Andrea AD, Glover TW (2005) The Fanconi anemia pathway is required for the DNA replication stress response and for the regulation of common fragile site stability. Hum Mol Genet 14(5):693-701. doi:10.1093/hmg/ddi065

80. Boyer AS, Grgurevic S, Cazaux C, Hoffmann JS (2013) The human specialized DNA polymerases and non-B DNA: vital relationships to preserve genome integrity. $\mathrm{J}$ Mol Biol 425(23):4767-4781. doi:10.1016/j.jmb.2013.09.022

81. Bhat A, Andersen PL, Qin Z, Xiao W (2013) Rev3, the catalytic subunit of Polzeta, is required for maintaining fragile site stability in human cells. Nucleic Acids Res 41(4):2328-2339. doi:10.1093/nar/gks1442

82. Walsh E, Wang X, Lee MY, Eckert KA (2013) Mechanism of replicative DNA polymerase delta pausing and a potential role for DNA polymerase kappa in common fragile site replication. J Mol Biol 425(2):232-243. doi:10.1016/j.jmb.2012.11.016

83. Franchitto A, Pichierri P (2011) Understanding the molecular basis of common fragile sites instability: role of the proteins involved in the recovery of stalled replication forks. Cell Cycle 10(23):4039-4046. doi:10.4161/cc.10.23.18409

84. Lu X, Parvathaneni S, Hara T, Lal A, Sharma S (2013) Replication stress induces specific enrichment of RECQ1 at common fragile sites FRA3B and FRA16D. Mol Cancer 12(1):29. doi:10. 1186/1476-4598-12-29

85. Dillon LW, Pierce LC, Lehman CE, Nikiforov YE, Wang YH (2013) DNA topoisomerases participate in fragility of the oncogene RET. PLoS ONE 8(9):e75741. doi:10.1371/journal. pone. 0075741

86. Mason JM, Das I, Arlt M, Patel N, Kraftson S, Glover TW, Sekiguchi JM (2013) The SNM1B/APOLLO DNA nuclease functions in resolution of replication stress and maintenance of common fragile site stability. Hum Mol Genet 22(24):49014913. doi: $10.1093 / \mathrm{hmg} / \mathrm{ddt} 340$

87. Safran M, Dalah I, Alexander J, Rosen N, Iny Stein T, Shmoish M, Nativ N, Bahir I, Doniger T, Krug H, Sirota-Madi A, Olender T, Golan Y, Stelzer G, Harel A, Lancet D (2010) GeneCards Version 3: the human gene integrator. Database (Oxford) 2010:baq020. doi:10.1093/database/baq020

88. Kinsella RJ, Kahari A, Haider S, Zamora J, Proctor G, Spudich G, Almeida-King J, Staines D, Derwent P, Kerhornou A, Kersey P, Flicek P (2011) Ensembl BioMarts: a hub for data retrieval across taxonomic space. Database (Oxford) 2011:bar030. doi:10.1093/database/bar030

89. Kanehisa M, Goto S, Sato Y, Furumichi M, Tanabe M (2012) KEGG for integration and interpretation of large-scale molecular data sets. Nucleic Acids Res 40(Database issue):D109D114. doi:10.1093/nar/gkr988

90. Iakovleva TK, Monakhov AS, Moiseenko VM (1992) Chromosomal restructurings and the distribution of chromosome 
fragile sites in the peripheral blood lymphocytes in a breast cancer patient after cytostatic therapy. Tsitologiia 34(2):77-83

91. Moriarty HT, Webster LR (2003) Fragile sites and bladder cancer. Cancer Genet Cytogenet 140(2):89-98

92. Hormozian F, Schmitt JG, Sagulenko E, Schwab M, Savelyeva L (2007) FRA1E common fragile site breaks map within a 370kilobase pair region and disrupt the dihydropyrimidine dehydrogenase gene (DPYD). Cancer Lett 246(1-2):82-91. doi:10.1016/j.canlet.2006.02.004

93. Pelliccia F, Limongi MZ, Gaddini L, Rocchi A (1998) Assignment of FRA1H common fragile site to human chromosome band 1q42.1 proximal to the nuclear NAD+ ADP-ribosyltransferase gene (ADPRT) and to the main 5S rRNA gene locus. Cytogenet Cell Genet 82(1-2):121-122

94. Lamparska K, Clark J, Babilonia G, Bedell V, Yip W, Smith SS (2012) 2'-Deoxyriboguanylurea, the primary breakdown product of 5-aza-2'-deoxyribocytidine, is a mutagen, an epimutagen, an inhibitor of DNA methyltransferases and an inducer of 5-azacytidine-type fragile sites. Nucleic Acids Res 40(19):97889801. doi:10.1093/nar/gks706

95. Lai LA, Kostadinov R, Barrett MT, Peiffer DA, Pokholok D, Odze R, Sanchez CA, Maley CC, Reid BJ, Gunderson KL, Rabinovitch PS (2010) Deletion at fragile sites is a common and early event in Barrett's esophagus. Mol Cancer Res 8(8):10841094. doi:10.1158/1541-7786.MCR-09-0529

96. IJdo JW, Baldini A, Wells RA, Ward DC, Reeders ST (1992) FRA2B is distinct from inverted telomere repeat arrays at $2 \mathrm{q} 13$. Genomics 12(4):833-835

97. Blumrich A, Zapatka M, Brueckner LM, Zheglo D, Schwab M, Savelyeva L (2011) The FRA2C common fragile site maps to the borders of MYCN amplicons in neuroblastoma and is associated with gross chromosomal rearrangements in different cancers. Hum Mol Genet 20(8):1488-1501. doi:10.1093/hmg/ ddr027

98. Luo WJ, Takakuwa T, Ham MF, Wada N, Liu A, Fujita S, Sakane-Ishikawa E, Aozasa K (2004) Epstein-Barr virus is integrated between REL and BCL-11A in American Burkitt lymphoma cell line (NAB-2). Lab Invest 84(9):1193-1199. doi:10.1038/labinvest.3700152

99. Limongi MZ, Pelliccia F, Rocchi A (1997) Assignment of the human nebulin gene (NEB) to chromosome band 2q24.2 and the alpha 1 (III) collagen gene (COL3A1) to chromosome band 2q32.2 by in situ hybridization; the FRA2G common fragile site lies between the two genes in the $2 \mathrm{q} 31$ band. Cytogenet Cell Genet 77(3-4):259-260

100. Limongi MZ, Pelliccia F, Gaddini L, Rocchi A (2000) Clustering of two fragile sites and seven homeobox genes in human chromosome region 2q31->q32.1. Cytogenet Cell Genet 90(1-2):151-153

101. Saitoh T, Hirai M, Katoh M (2001) Molecular cloning and characterization of human Frizzled-5 gene on chromosome 2q33.3-q34 region. Int J Oncol 19(1):105-110

102. Parmentier M, Passage E, Mattei MG, Vassart G (1991) A new human hypervariable locus (K29) maps to the q37.3 region of chromosome 2 and reveals a fingerprint. Genomics 11(3):760762

103. Mulatinho MV, de Carvalho Serao CL, Scalco F, Hardekopf D, Pekova S, Mrasek K, Liehr T, Weise A, Rao N, Llerena JC Jr (2012) Severe intellectual disability, omphalocele, hypospadia and high blood pressure associated to a deletion at $2 \mathrm{q} 22.1 \mathrm{q} 22.3$ : case report. Mol Cytogenet 5(1):30. doi:10.1186/1755-8166-530

104. Schuffenhauer S, Lederer G, Murken J (1996) A heritable folatesensitive fragile site on chromosome 2p 11.2 (FRA2L). Chromosome Res 4(3):252-254
105. Pelliccia F, Bosco N, Rocchi A (2010) Breakages at common fragile sites set boundaries of amplified regions in two leukemia cell lines K562-molecular characterization of FRA2H and localization of a new CFS FRA2S. Cancer Lett 299(1):37-44. doi:10.1016/j.canlet.2010.08.001

106. Li XZ, Yan ZA, Zhou XT (1986) The effect of 1-beta-D-arabinofuranosyl-cytosine on the expression of the common fragile site at 3p14. Hum Genet 74(4):444-446

107. Darai-Ramqvist E, Sandlund A, Muller S, Klein G, Imreh S, Kost-Alimova M (2008) Segmental duplications and evolutionary plasticity at tumor chromosome break-prone regions. Genome Res 18(3):370-379. doi:10.1101/gr.7010208

108. Bolivar J, Garcia-Cozar FJ, Astola A, Iglesias C, Pendon C, Valdivia MM (2001) Genomic structure and chromosome location of the human gene encoding the zinc finger autoantigen ZNF330. Cytogenet Cell Genet 93(3-4):234-238

109. Rozier L, El-Achkar E, Apiou F, Debatisse M (2004) Characterization of a conserved aphidicolin-sensitive common fragile site at human $4 \mathrm{q} 22$ and mouse $6 \mathrm{C} 1$ : possible association with an inherited disease and cancer. Oncogene 23(41):6872-6880. doi:10.1038/sj.onc.1207809

110. Zimonjic DB, Durkin ME, Keck-Waggoner CL, Park SW, Thorgeirsson SS, Popescu NC (2003) SMAD5 gene expression, rearrangements, copy number, and amplification at fragile site FRA5C in human hepatocellular carcinoma. Neoplasia 5(5):390-396

111. Olavesen MG, Davies AF, Broxholme SJ, Wixon JL, Senger G, Nizetic D, Campbell RD, Ragoussis J (1995) An integrated map of human chromosome 6p23. Genome Res 5(4):342-358

112. Thorland EC, Myers SL, Persing DH, Sarkar G, McGovern RM, Gostout BS, Smith DI (2000) Human papillomavirus type 16 integrations in cervical tumors frequently occur in common fragile sites. Cancer Res 60(21):5916-5921

113. Kahkonen M (1988) Population cytogenetics of folate-sensitive fragile sites. I. Common fragile sites. Hum Genet 80(4):344-348

114. Morelli C, Sherratt T, Trabanelli C, Rimessi P, Gualandi F, Greaves MJ, Negrini M, Boyle JM, Barbanti-Brodano G (1997) Characterization of a 4-Mb region at chromosome 6q21 harboring a replicative senescence gene. Cancer Res 57(19):41534157

115. Fechter A, Buettel I, Kuehnel E, Schwab M, Savelyeva L (2007) Cloning of genetically tagged chromosome break sequences reveals new fragile sites at $6 \mathrm{p} 21$ and $13 \mathrm{q} 22$. Int $\mathrm{J}$ Cancer 120(11):2359-2367. doi:10.1002/ijc. 22564

116. Bosco N, Pelliccia F, Rocchi A (2010) Characterization of FRA7B, a human common fragile site mapped at the $7 \mathrm{p}$ chromosome terminal region. Cancer Genet Cytogenet 202(1):4752. doi:10.1016/j.cancergencyto.2010.06.008

117. Zlotorynski E, Rahat A, Skaug J, Ben-Porat N, Ozeri E, Hershberg R, Levi A, Scherer SW, Margalit H, Kerem B (2003) Molecular basis for expression of common and rare fragile sites. Mol Cell Biol 23(20):7143-7151

118. Shridhar V, Sun QC, Miller OJ, Kalemkerian GP, Petros J, Smith DI (1997) Loss of heterozygosity on the long arm of human chromosome 7 in sporadic renal cell carcinomas. Oncogene 15(22):2727-2733. doi:10.1038/sj.onc.1201448

119. Smith DI, Huang H, Wang L (1998) Common fragile sites and cancer (review). Int J Oncol 12(1):187-196

120. Ciullo M, Debily MA, Rozier L, Autiero M, Billault A, Mayau V, El Marhomy S, Guardiola J, Bernheim A, Coullin P, PiatierTonneau D, Debatisse M (2002) Initiation of the breakagefusion-bridge mechanism through common fragile site activation in human breast cancer cells: the model of PIP gene duplication from a break at FRA7I. Hum Mol Genet 11(23):2887-2894 
121. Helmrich A, Stout-Weider K, Matthaei A, Hermann K, Heiden T, Schrock E (2007) Identification of the human/mouse syntenic common fragile site FRA7K/Fra12C1-relation of FRA7K and other human common fragile sites on chromosome 7 to evolutionary breakpoints. Int J Cancer 120(1):48-54. doi:10.1002/ijc. 22049

122. Takahashi E, Hori T, O'Connell P, Leppert M, White R (1991) Mapping of the MYC gene to band 8q24.12-q24.13 by R-banding and distal to fra(8)(q24.11), FRA8E, by fluorescence in situ hybridization. Cytogenet Cell Genet 57(2-3):109-111

123. Kahkonen M, Tengstrom C, Alitalo T, Matilainen R, Kaski M, Airaksinen E (1989) Population cytogenetics of folate-sensitive fragile sites. II. Autosomal rare fragile sites. Hum Genet 82(1):3-8

124. Callahan G, Denison SR, Phillips LA, Shridhar V, Smith DI (2003) Characterization of the common fragile site FRA9E and its potential role in ovarian cancer. Oncogene 22(4):590-601. doi:10.1038/sj.onc.1206171

125. Sawinska M, Schmitt JG, Sagulenko E, Westermann F, Schwab M, Savelyeva L (2007) Novel aphidicolin-inducible common fragile site FRA9G maps to 9p22.2, within the C9orf39 gene. Genes Chromosomes Cancer 46(11):991-999. doi:10.1002/gcc. 20484

126. Cannizzaro LA, Aronson MM, Thiesen HJ (1993) Human zinc finger gene ZNF23 (Kox16) maps to a zinc finger gene cluster on chromosome 16q22, and ZNF32 (Kox30) to chromosome region 10q23-q24. Hum Genet 91(4):383-385

127. Sarafidou T, Kahl C, Martinez-Garay I, Mangelsdorf M, Gesk S, Baker E, Kokkinaki M, Talley P, Maltby EL, French L, Harder L, Hinzmann B, Nobile C, Richkind K, Finnis M, Deloukas P, Sutherland GR, Kutsche K, Moschonas NK, Siebert R, Gecz J, European Collaborative Consortium for the Study of ADLTE (2004) Folate-sensitive fragile site FRA10A is due to an expansion of a CGG repeat in a novel gene, FRA10AC1, encoding a nuclear protein. Genomics 84(1):69-81. doi:10.1016/ j.ygeno.2003.12.017

128. Voiculescu I, Back E, Schempp W (1991) Homozygous condition for a BrdU-requiring fragile site on chromosome 12. Hum Genet 86(4):416-417

129. Gandhi M, Dillon LW, Pramanik S, Nikiforov YE, Wang YH (2010) DNA breaks at fragile sites generate oncogenic RET/ PTC rearrangements in human thyroid cells. Oncogene 29(15):2272-2280. doi:10.1038/onc.2009.502

130. Ma K, Qiu L, Mrasek K, Zhang J, Liehr T, Quintana LG, Li Z (2012) Common fragile sites: genomic hotspots of DNA damage and carcinogenesis. Int J Mol Sci 13(9):11974-11999. doi:10. 3390/ijms 130911974

131. Hagemeijer A, Lafage M, Mattei MG, Simonetti J, Smit E, de Lapeyriere O, Birnbaum D (1991) Localization of the HST/ FGFK gene with regard to $11 \mathrm{q} 13$ chromosomal breakpoint and fragile site. Genes Chromosomes Cancer 3(3):210-214

132. Simmers RN, Sutherland GR (1988) Further localization of ETS1 indicates that the chromosomal rearrangement in Ewing sarcoma does not occur at fra(11)(q23). Hum Genet 78(2):144-147

133. Fechter A, Buettel I, Kuehnel E, Savelyeva L, Schwab M (2007) Common fragile site FRA11G and rare fragile site FRA11B at 11q23.3 encompass distinct genomic regions. Genes Chromosomes Cancer 46(1):98-106. doi:10.1002/gcc.20389

134. Bester AC, Schwartz M, Schmidt M, Garrigue A, Hacein-BeyAbina S, Cavazzana-Calvo M, Ben-Porat N, Von Kalle C, Fischer A, Kerem B (2006) Fragile sites are preferential targets for integrations of MLV vectors in gene therapy. Gene Ther 13(13):1057-1059. doi:10.1038/sj.gt.3302752

135. Reshmi SC, Huang X, Schoppy DW, Black RC, Saunders WS, Smith DI, Gollin SM (2007) Relationship between FRA11F and
$11 \mathrm{q} 13$ gene amplification in oral cancer. Genes Chromosomes Cancer 46(2):143-154. doi:10.1002/gcc.20394

136. Bester AC, Kafri M, Maoz K, Kerem B (2013) Infection with retroviral vectors leads to perturbed DNA replication increasing vector integrations into fragile sites. Sci Rep 3:2189. doi:10. 1038/srep02189

137. Tommerup N, Leffers H (1996) Assignment of human KH-boxcontaining genes by in situ hybridization: hNRNPK maps to 9q21.32-q21.33, PCBP1 to 2p12-p13, and PCBP2 to 12q13.12q13.13, distal to FRA12A. Genomics 32(2):297-298. doi:10. 1006/geno.1996.0121

138. Amarose AP, Huttenlocher PR, Sprudzs RM, Laitsch TJ, Pettenati MJ (1987) A heritable fragile 12q24.13 segregating in a family with the fragile X chromosome. Hum Genet 75(1):4-6

139. Savelyeva L, Sagulenko E, Schmitt JG, Schwab M (2006) The neurobeachin gene spans the common fragile site FRA13A. Hum Genet 118(5):551-558. doi:10.1007/s00439-005-0083-z

140. Vincent JB, Neves-Pereira ML, Paterson AD, Yamamoto E, Parikh SV, Macciardi F, Gurling HM, Potkin SG, Pato CN, Macedo A, Kovacs M, Davies M, Lieberman JA, Meltzer HY, Petronis A, Kennedy JL (2000) An unstable trinucleotide-repeat region on chromosome 13 implicated in spinocerebellar ataxia: a common expansion locus. Am J Hum Genet 66(3):819-829. doi: $10.1086 / 302803$

141. Zhu Y, McAvoy S, Kuhn R, Smith DI (2006) RORA, a large common fragile site gene, is involved in cellular stress response. Oncogene 25(20):2901-2908. doi:10.1038/sj.onc.1209314

142. Simmers RN, Mulley JC, Hyland VJ, Callen DF, Sutherland GR (1987) Mapping the human alpha globin gene complex to 16p13.2-pter. J Med Genet 24(12):761-766

143. Fratini A, Simmers RN, Callen DF, Hyland VJ, Tischfield JA, Stambrook PJ, Sutherland GR (1986) A new location for the human adenine phosphoribosyltransferase gene (APRT) distal to the haptoglobin (HP) and fra(16)(q23)(FRA16D) loci. Cytogenet Cell Genet 43(1-2):10-13

144. Simmers RN, Sutherland GR, West A, Richards RI (1987) Fragile sites at $16 \mathrm{q} 22$ are not at the breakpoint of the chromosomal rearrangement in AMMoL. Science 236(4797):92-94

145. Dooley TP, Mitchison HM, Munroe PB, Probst P, Neal M, Siciliano MJ, Deng Z, Doggett NA, Callen DF, Gardiner RM et al (1994) Mapping of two phenol sulphotransferase genes, STP and STM, to 16p: candidate genes for Batten disease. Biochem Biophys Res Commun 205(1):482-489

146. Karkera JD, Balan KV, Yoshikawa T, Lipman TO, Korman L, Sharma A, Patterson RH, Sani N, Detera-Wadleigh SD, Wadleigh RG (1999) Systematic screening of chromosome 18 for loss of heterozygosity in esophageal squamous cell carcinoma. Cancer Genet Cytogenet 111(1):81-86

147. Capello D, Scandurra M, Poretti G, Rancoita PM, Mian M, Gloghini A, Deambrogi C, Martini M, Rossi D, Greiner TC, Chan WC, Ponzoni M, Moreno SM, Piris MA, Canzonieri V, Spina M, Tirelli U, Inghirami G, Rinaldi A, Zucca E, Favera RD, Cavalli F, Larocca LM, Kwee I, Carbone A, Gaidano G, Bertoni F (2010) Genome wide DNA-profiling of HIV-related B-cell lymphomas. Br J Haematol 148(2):245-255. doi:10.1111/ j.1365-2141.2009.07943.x

148. Debacker K, Winnepenninckx B, Ben-Porat N, FitzPatrick D, Van Luijk R, Scheers S, Kerem B, Frank Kooy R (2007) FRA18C: a new aphidicolin-inducible fragile site on chromosome $18 \mathrm{q} 22$, possibly associated with in vivo chromosome breakage. J Med Genet 44(5):347-352. doi:10.1136/jmg.2006. 044628

149. Shen Y, Baker E, Callen DF, Sutherland GR, Willson TA, Rakar S, Gough NM (1992) Localization of the human GM-CSF receptor beta chain gene (CSF2RB) to chromosome 22q12.2$>$ q13.1. Cytogenet Cell Genet 61(3):175-177 
150. Culjkovic B, Stojkovic O, Savic D, Zamurovic N, Nesic M, Major T, Keckarevi D, Romac S, Zamurovi B, Vukosavic S (2000) Comparison of the number of triplets in SCA1, MJD/ SCA3, HD, SBMA, DRPLA, MD, FRAXA and FRDA genes in schizophrenic patients and a healthy population. Am J Med Genet 96(6):884-887

151. Ledbetter SA, Ledbetter DH (1988) A common fragile site at Xq27: theoretical and practical implications. Am J Hum Genet 42(5):694-702

152. Sharma D, Gupta M, Thelma BK (2001) Expansion mutation frequency and CGG/GCC repeat polymorphism in FMR1 and FMR2 genes in an Indian population. Genet Epidemiol 20(1):129-144. doi:10.1002/1098-2272(200101)20:1<129:AIDGEPI11>3.0.CO;2-2

153. Shaw MA, Chiurazzi P, Romain DR, Neri G, Gecz J (2002) A novel gene, FAM11A, associated with the FRAXF CpG island is transcriptionally silent in FRAXF full mutation. Eur $\mathrm{J}$ Hum Genet 10(11):767-772. doi:10.1038/sj.ejhg.5200881

154. Curatolo A, Limongi ZM, Pelliccia F, Rocchi A (2007) Molecular characterization of the human common fragile site FRA1H. Genes Chromosomes Cancer 46(5):487-493. doi:10. 1002/gcc. 20432

155. Limongi MZ, Pelliccia F, Rocchi A (2003) Characterization of the human common fragile site FRA2G. Genomics 81(2):93-97

156. Brueckner LM, Sagulenko E, Hess EM, Zheglo D, Blumrich A, Schwab M, Savelyeva L (2012) Genomic rearrangements at the FRA2H common fragile site frequently involve non-homologous recombination events across LTR and L1(LINE) repeats. Hum Genet 131(8):1345-1359. doi:10.1007/s00439-012-1165-3

157. Becker NA, Thorland EC, Denison SR, Phillips LA, Smith DI (2002) Evidence that instability within the FRA3B region extends four megabases. Oncogene 21(57):8713-8722. doi:10. 1038/sj.onc. 1205950

158. Denison SR, Callahan G, Becker NA, Phillips LA, Smith DI (2003) Characterization of FRA6E and its potential role in autosomal recessive juvenile parkinsonism and ovarian cancer.
Genes Chromosomes Cancer 38(1):40-52. doi:10.1002/gcc. 10236

159. Morelli C, Karayianni E, Magnanini C, Mungall AJ, Thorland E, Negrini M, Smith DI, Barbanti-Brodano G (2002) Cloning and characterization of the common fragile site FRA6F harboring a replicative senescence gene and frequently deleted in human tumors. Oncogene 21(47):7266-7276. doi:10.1038/sj.onc. 1205573

160. Huang H, Qian J, Proffit J, Wilber K, Jenkins R, Smith DI (1998) FRA7G extends over a broad region: coincidence of human endogenous retroviral sequences (HERV-H) and small polydispersed circular DNAs (spcDNA) and fragile sites. Oncogene 16(18):2311-2319. doi:10.1038/sj.onc.1200202

161. Mishmar D, Rahat A, Scherer SW, Nyakatura G, Hinzmann B, Kohwi Y, Mandel-Gutfroind Y, Lee JR, Drescher B, Sas DE, Margalit H, Platzer M, Weiss A, Tsui LC, Rosenthal A, Kerem B (1998) Molecular characterization of a common fragile site (FRA7H) on human chromosome 7 by the cloning of a simian virus 40 integration site. Proc Natl Acad Sci U S A 95(14):8141-8146

162. Ferber MJ, Thorland EC, Brink AA, Rapp AK, Phillips LA, McGovern R, Gostout BS, Cheung TH, Chung TK, Fu WY, Smith DI (2003) Preferential integration of human papillomavirus type 18 near the c-myc locus in cervical carcinoma. Oncogene 22(46):7233-7242. doi:10.1038/sj.onc.1207006

163. Ried K, Finnis M, Hobson L, Mangelsdorf M, Dayan S, Nancarrow JK, Woollatt E, Kremmidiotis G, Gardner A, Venter D, Baker E, Richards RI (2000) Common chromosomal fragile site FRA16D sequence: identification of the FOR gene spanning FRA16D and homozygous deletions and translocation breakpoints in cancer cells. Hum Mol Genet 9(11):1651-1663

164. Arlt MF, Miller DE, Beer DG, Glover TW (2002) Molecular characterization of FRAXB and comparative common fragile site instability in cancer cells. Genes Chromosomes Cancer 33(1):82-92 